\title{
Construction of spirolactones with concomitant formation of the fused quaternary centre - application to the synthesis of natural products
}

\author{
Alexandra Bartoli, Fabien Rodier, Laurent Commeiras, Jean-Luc Parrain and Gaëlle Chouraqui*
}

\begin{abstract}
Polycyclic structures fused at a central carbon are of great interest due to their appealing conformational features and their structural implications in biological systems. Although progress in the development of synthetic methodologies towards such structures has been impressive, the stereoselective construction of such quaternary stereocentres remains a significant challenge in the total synthesis of natural products. This review highlights the progress in the formation of 1oxaspiro[4.n]alkan-2-ones $(2 \leq n \leq 7)$ with concomitant formation of the quaternary spiro centre.
\end{abstract}

1 Introduction

2 Oxidation: dearomatisation of phenol to quinone

2.1 Hypervalent iodine(III)

2.2 CAN oxidative coupling

3 Reductive cross-coupling

4 Radical-based approaches

5 Furanyl dienolate-based cyclisation

5.1 Alkylation

5.2 Addition onto an imine (vinylogous Mannich)

5.3 Vinylogous aldol reaction

6 Cationic rearrangement

7 Use of organometallic derivatives

7.1 Double acylation

7.2 Reformatsky-type reaction

7.3 Carbonyl insertion

8 Halolactonisation

9 Pericyclic-type reactions

9.1 Electrocyclisation

$9.2[2+1]$ photocycloaddition

$9.3[2+2]$ cycloaddition

9.4 Diels-Alder reaction

$9.5[3+2]$-type cyclisation

10 Miscellaneous

10.1 1,6-Addition

10.2 Dyotropic rearrangement

11 Conclusion

12 Acknowledgements

13 References

Aix-Marseille Université, Institut des Sciences Moléculaires de Marseille iSm2 - UMR CNRS 6263, Campus Saint Jérôme, Service 532, 13397 Marseille Cedex 20, France. E-mail: gaelle.chouraqui@univ-cezanne.fr; Fax: +33 4-91289187; Tel: +33 4-91289188

\section{Introduction}

Spirolactones containing natural products represent a large class of structurally diverse molecules exhibiting a wide range of biological activities. Key examples include: drospirenone (Fig. 1), a synthetic progestin that is a component of certain birth control formulations such as Yasmin $28^{\circledR}$ (marketed by Bayer Schering Pharma), ${ }^{1}$ the world's most popular contraceptive pill, ranked in the top 200 brand-name drugs by retail dollars in 2008; ${ }^{2}$ and abyssomicin C, a potent antibacterial agent against Gram-positive bacteria, including resistant Staphylococcus aureus strains (MIC for a methicillin-resistant strain $=4 \mu \mathrm{g} \mathrm{mL}^{-1}$; MiC for a vancomycin-resistant strain = $\left.13 \mu \mathrm{g} \mathrm{mL}^{-1}\right){ }^{3}$

The stereoselective synthesis of spirolactones is a challenging task, requiring control in the construction of the quaternary carbon. ${ }^{4}$ The presence of the sterically constrained spiro structure in various natural products of biological importance also adds to the interest in investigations of spiro compounds. Most of the methods to access spirolactones involve an intramolecular esterification reaction, which is favoured for entropic reasons. A number of natural products have been obtained by this

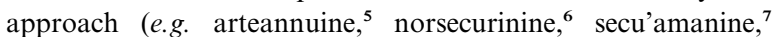
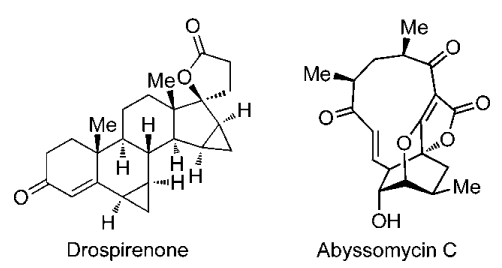

Fig. 1 
stemonamide $\left.{ }^{8}\right)$. Since this strategy requires the prior installation of the tertiary alcohol, these methods will not be covered within this review. Instead, we will focus on transformations involving the creation of the spirolactone concomitant to cyclisation with the fused stereocentre - potentially powerful synthetic

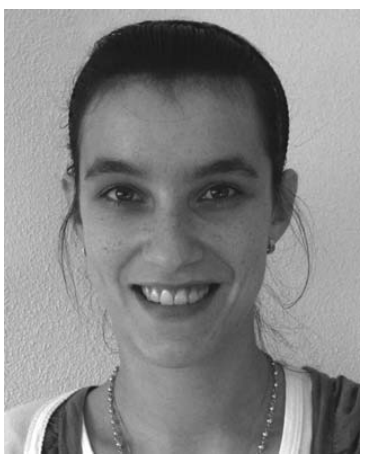

Alexandra Bartoli

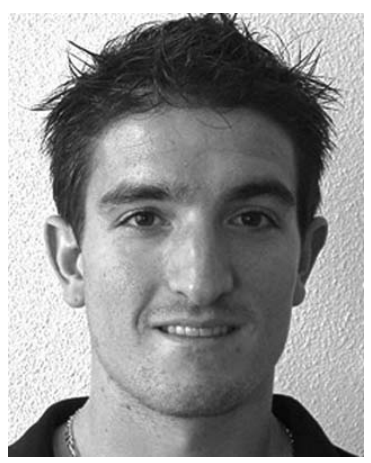

Fabien Rodier

$[5+2]$ cycloaddition.

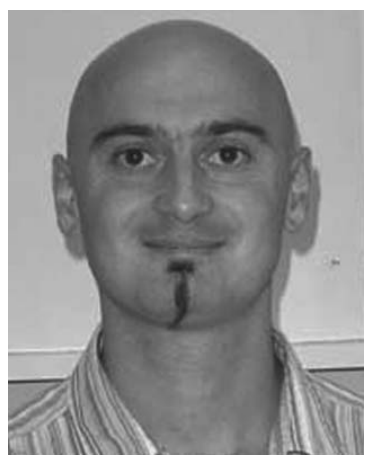

Laurent Commeiras

Alexandra Bartoli was born in Marseille (France) in October 1984. She obtained her BSc in chemistry in 2006 and her MSc in 2008, both from the Université Paul Cézanne in Marseille, where she is currently pursuing her PhD under the supervision of Dr Gaëlle Chouraqui and Dr Jean-Luc Parrain. Her research focuses on the development of new methods to access polycyclic compounds and spirolactones.

Fabien Rodier was born in Nîmes (France) in June 1984. In 2006, he joined the University of Montpellier (France) where he was awarded his BSc in chemistry. He then moved to the École Nationale Supérieure de Chimie de Montpellier (ENSCM), where he obtained his MSc in chemistry. He is currently pursuing his PhD under the supervision of $\mathrm{Dr}$ Gaëlle Chouraqui, Dr Laurent Commeiras and Dr Jean-Luc Parrain at the Université Paul Cézanne in Marseille (France).

His research focuses on the synthesis of spirolactone moieties using Laurent Commeiras was born in Marseille (France) in 1975. After studying chemistry at the Université Paul Cézanne in Marseille, he received his $P h D$ degree in 2002 under the supervision of Dr Jean-Luc Parrain, working on the total synthesis of terpenoids isolated from algae of the order Caulerpales. After a postdoctoral position in the laboratory of Professor Sir Jack E. Baldwin at the University of Oxford (UK), he became Lecturer at the University of Marseille. His main research interests include the total synthesis of natural and biologically active compounds. transformations allowing the formation of a quaternary stereocentre (still one of the most challenging tasks in organic synthesis).

Herein, we will cover the synthesis of spirobutenolides and more specifically the 1-oxaspiro[4.n]alkan-2-ones $(2 \leq n \leq 7)$ (Fig. 2).

This review will discuss different methods to create simultaneously the spirolactone and the quaternary spiro stereocentre and their application to the synthesis of natural products. This will be divided either into categories of reaction or species used: oxidation, reduction, radicals, dienolate, cationic rearrangement, organometallic derivatives, halolactonisation, pericyclic reactions.

Spirocyclic structures have already been the subject of a number of reviews, ${ }^{9,10}$ including those devoted to spiroketals ${ }^{11}$ and spirocyclic ethers, ${ }^{12}$ and the reader is directed to these articles for discussion of these topics.

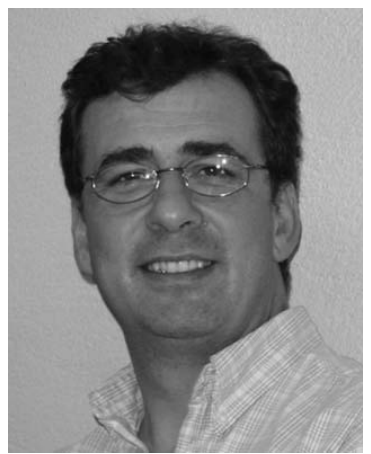

Jean-Luc Parrain
Jean-Luc Parrain obtained his PhD in Chemistry at the University of Nantes (France) under the supervision of Professor Jean-Paul Quintard. After post-doctoral studies in the laboratory of Professor Steve Davies at the University of Oxford (UK), he joined the CNRS as "chargé de recherche" at the laboratory of Organic Synthesis of the University of Nantes. In 1995, he moved to the University of Marseille and then was appointed a CNRS "directeur de recherches" in 2001. His research interests include new catalytic reactions toward new synthetic methods, development of new organotin and silicon reagents and total synthesis of natural compounds.

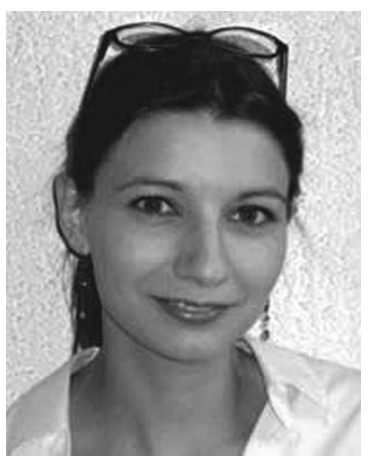

Gaëlle Chouraqui
Gaëlle Chouraqui obtained her PhD in 2003, from the Université Pierre et Marie Curie (Paris, France), where she worked under the guidance of Professor Max Malacria and Dr Corinne Aubert. After a twoyear stay as a Postdoctoral Research Fellow with Professor James H. Rigby at Wayne State University (US), she returned to Europe and completed a further year as a Postdoctoral Research Fellow in Professor Ian Paterson's laboratory at Cambridge University. She was appointed CNRS Tenured-Researcher in 2007 at Aix-Marseille University (France), and her research interests are centred on new methods for the synthesis of natural products. 


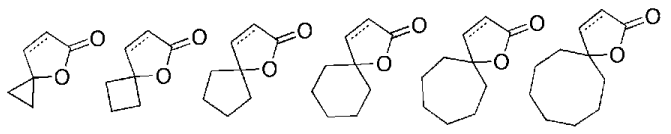

Fig. 2

\section{Oxidation: dearomatisation of phenol to quinone}

The prevalence of $p$-spiroquinones in natural products, biologically active molecules and ligands underscores the importance of devising general methods for their efficient construction. Quinones are commonly prepared by chemical oxidation, ${ }^{13}$ electrochemical oxidation ${ }^{14}$ or monohydrolysis of the corresponding quinone bisacetals. Phenolic oxidation has often been implicated as the pivotal step in the biosynthesis of natural product incorporating a $p$-spiroquinone moiety.

In 1987, Tamura ${ }^{15}$ reported an iodine(III)-induced dearomatisation of phenols to quinones. Later on Kobayashi described a novel cerium(IV)-mediated oxidative coupling of 2,6-dibromophenol derivatives. ${ }^{16}$ Both these methods have been used extensively in spirolactone synthesis.

\subsection{Hypervalent iodine(III)}

In a typical procedure, a solution of $p$-phenol $\mathbf{1}$ in anhydrous acetonitrile was treated with bis(trifluoroacetoxy)-iodobenzene (BTIB) in presence of pyridine (Scheme 1). After oxidation of this phenol ring to the corresponding quinone, intramolecular ipso-trapping by the carboxy nucleophile took place, leading to the spiro compound $\mathbf{2}$ in $86 \%$ yield.

Later on, Hara ${ }^{17}$ described a one-pot procedure utilising bis(acetoxy)-iodobenzene (BAIB) followed by an aqueous sodium chloride or bromide quench to access dihalodienone spirolactone $\mathbf{5}$ from phenol $\mathbf{3}$ (Scheme 2). Three equivalents of BAIB were required, but this reagent is much less expensive than the previously used BTIB. This domino process allowed the formation of three new $\sigma$-bonds together with a stereogenic quaternary centre.

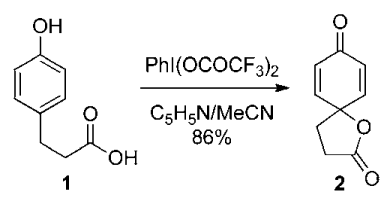

Scheme 1

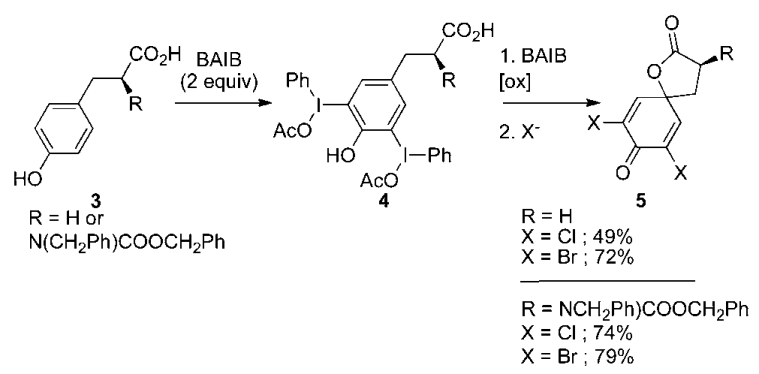

Scheme 2
This methodology was next extended to a domino reaction featuring the Wessely-type intramolecular oxidation ${ }^{18}$ followed by an intermolecular Diels-Alder reaction (Scheme 3). ${ }^{19}$ Unlike previously reported examples, phenol 6 bears the carboxylic acid suitably tethered at the ortho position. An additional functional group para to the alcohol circumvents any trapping at that position. Treatment of phenol $\mathbf{6}$ with BTIB provided intermediate diene 8 , which was then set to undergo [4 +2$]$ cycloaddition with a range of dienophiles $\mathbf{9 a - f}$ present in the reaction mixture.

Alkenes 9a-d proved to be good dienophiles, and provided the corresponding polycyclic structures $7\left(\mathrm{R}^{\prime}=\mathrm{R}^{\prime \prime}=\mathrm{H}\right)$ as single diastereomers in yields ranging from 50 to $89 \%$. The diastereoselectivity of the transformation is explained by attack of the dienophile occurring from the less hindered oxygen-bearing face of the diene.

Alkynes are also competent dienophiles but require higher temperatures, and yields are lower than with their olefinic counterparts. Electron-deficient dienes $8(\mathrm{R}=\mathrm{I}$ or $\mathrm{Ac}$ and $\mathrm{R}=\mathrm{R}^{\prime}=\mathrm{H}$ ) when reacted with electron-rich alkenes $(\mathbf{9 e}-\mathbf{f})$ gave excellent yields (from 74 to $91 \%$ yield) in this inverse-electrondemand Diels-Alder reaction. Single diastereomers were observed here also.

Finally, Wood et al. showed that this reaction proceeded with good substrate-based control. Whilst a methyl group $\alpha$ to the carboxylic acid $6\left(\mathrm{R}=\mathrm{R}^{\prime}=\mathrm{Me}\right.$ and $\left.\mathrm{R}^{\prime \prime}=\mathrm{H}\right)$ provided little stereo-induction, leading to a mixture of two diastereomers in a $1: 1$ ratio, a methyl group at the $\beta$ position $6\left(\mathrm{R}=\mathrm{R}^{\prime \prime}=\mathrm{Me}\right.$ and $\mathrm{R}^{\prime}=\mathrm{H}$ ) provided cycloadduct 7 as a single diastereomer. Hypervalent iodine(III) has the advantage of using an environmentally benign organo-oxidant, which is more efficient than DDQ or ferric chloride.

Kita recently made an important breakthrough by perfecting the first Wessely-type reaction using a catalytic amount of iodine(III $)^{20}$ and subsequently by developing a chiral hypervalent iodine(III) reagent for the enantioselective dearomatisation of phenols. ${ }^{21}$ In the catalytic version the authors demonstrated that hypervalent iodine(III) could be generated in situ from 4-iodotoluene (12) by using $m$-CPBA as a co-oxidant in presence of triflic acid as an additive (Scheme 4). The intermediate 13 mediated the oxidation of phenols 10 into spiro-quinones 11 with concomitant regeneration of 4-iodotoluene $\mathbf{1 2}$ in yields ranging from 66 to $91 \%$. This versatile procedure was performed at room

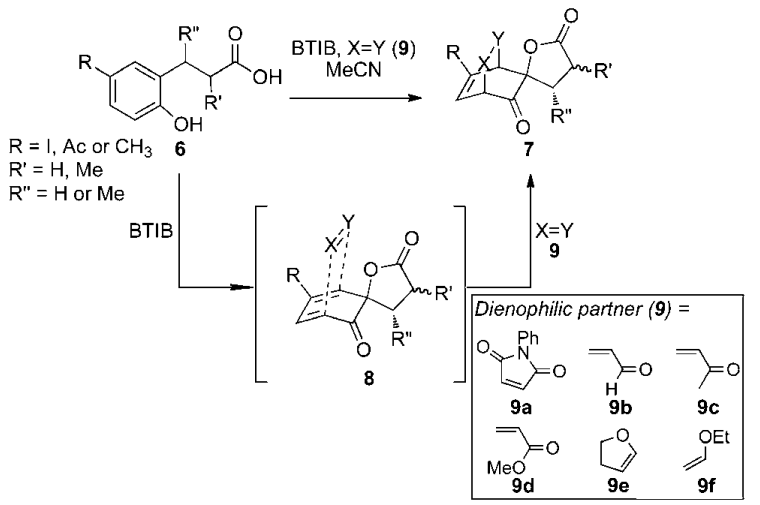

Scheme 3 


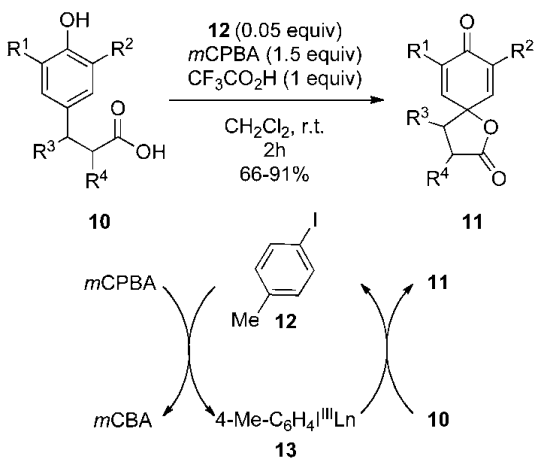

Scheme 4

temperature and required only 0.05 equivalents of catalyst $\mathbf{1 2}$. The authors did not mention the diastereoselectivity of the reaction.

In further experiment, Kita et al. designed and synthesised a recyclable catalyst 14 (Scheme 5). Its extraction from the reaction mixture, in nearly quantitative yield, was facilitated by its insolubility in methanol.

In the first example of its kind, Kita and co-workers have designed and implemented a chiral iodine(III) oxidant for the enantioselective formation of spirolactones. Chiral iodine(III) reagent $(R)-\mathbf{1 5}$, which has a rigid spirobiindane skeleton (Scheme $6)$, mediates the formation of ortho-spirolactone (+)-18 in high yield $(86 \%)$ with a significant level of enantioselectivity $(86 \% e e)$. Early studies also demonstrated that a catalytic version was possible by using $30 \mathrm{~mol} \%$ of chiral iodoarene $(R)-\mathbf{1 6}$ and $\mathrm{m}$ CPBA as a co-oxidant in the presence of acetic acid; however, the observed enantiomeric excess was significantly lower $(69 \% e e)$.

In early 2010, Ishihara et al. developed a conformationally flexible $C_{2}$-symmetric chiral iodoarene $19,{ }^{22}$ which, upon reaction with an oxidant, generated in situ the effective catalyst iodosylarene 20 (Scheme 7). The authors believed that a structural chiral environment is imparted by either hydrogen-bonding (see 20a) or $\mathrm{n}-\sigma^{*}$ intramolecular interactions (see 20b).

Treatment of 1-naphthol derivatives 21 with precatalyst 19 (10 mol $\%)$ and $m$-CPBA (1.2-1.5 equiv) at $0{ }^{\circ} \mathrm{C}$ in a $2: 1$ mixture of chloroform and nitromethane (Scheme 8) provided $o$-spirolactones in good yield and enantiomeric excess (>83\% ee).

The hypervalent iodine(III) phenolic dearomatisation strategy has been applied with success to the synthesis of a range of natural products including aranorosin (22a) (Fig. 3) or

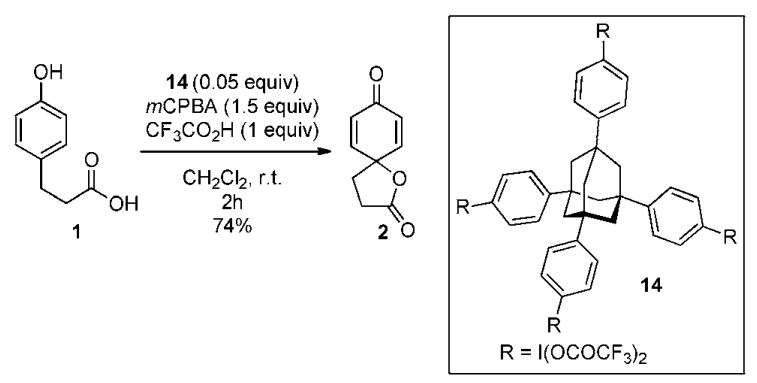

Scheme 5

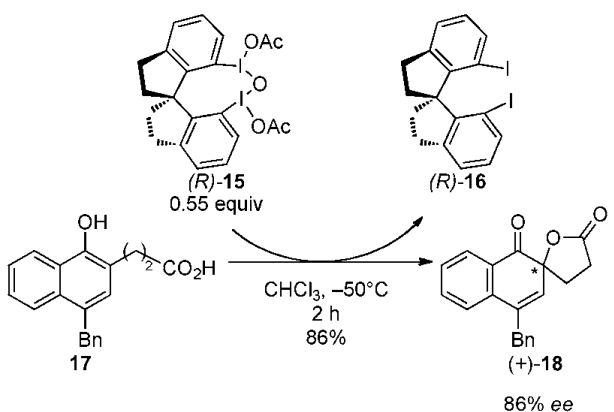

Scheme 6

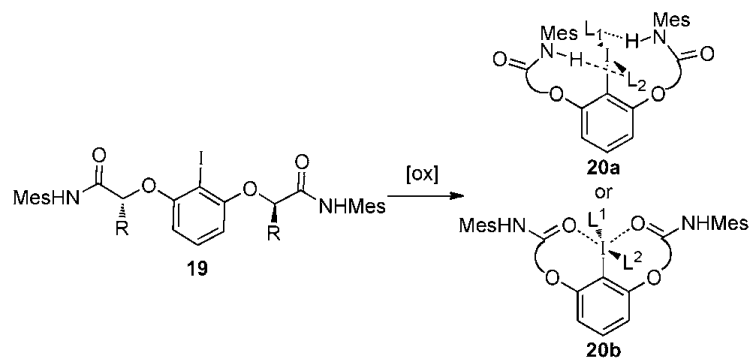

Scheme 7

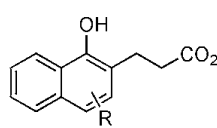

21

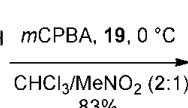

$83 \%$

(+)-scyphostatin (23) (vide infra), thereby illustrating the scope of the method.

Aranorosin (22a) was isolated in 1988 from the fermentation broth of the fungal strain Pseudoarachniotus roseus by Fehlhaber, Mukhopadhyay and co-workers. ${ }^{23}$ This highly

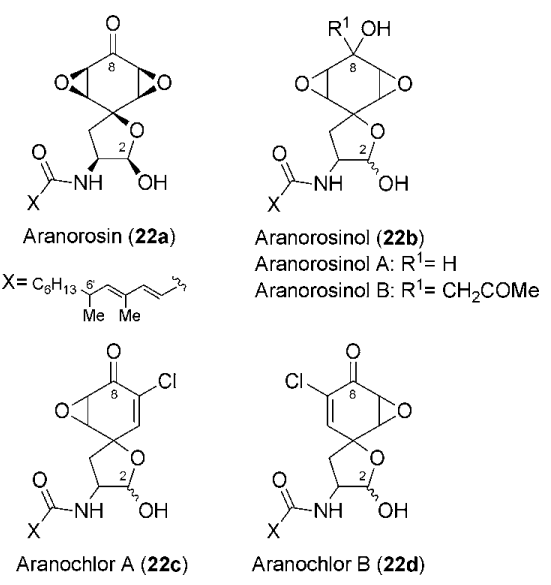

Fig. 3 
oxygenated tetracyclic compound incorporates seven stereocentres (five being contiguous) and two epoxides. Whilst the relative stereochemistry for aranorosin has been established by extensive NMR spectroscopic analysis together with chemical degradation, the stereochemistry of the remote C- $6^{\prime}$ stereocentre together with the absolute configuration remained undetermined. Aranorosin exhibits antitumour and antifungal properties in addition to antibiotic activity against both Gram-positive and Gram-negative bacteria, ${ }^{23 a, c}$ yeast and filamentous fungi (e.g. $\mathrm{MIC}=1.5 \mu \mathrm{g} \mathrm{mL}^{-1}$ for Staphylococcus aureus, Bacillus subtilis and Micrococcus luteus strains). Subsequently, fermentation of the same fungal strain led to the isolation of four more metabolites: aranorisinols A and B (which were reduced at C-8 and C-2; compare to 22a) ${ }^{24}$ and aranochlors $\mathrm{A}$ and $\mathrm{B}$ (monoepoxides). ${ }^{25}$ These compounds proved to be less active, therefore suggesting that the bicyclic core plays a crucial role in the antifungal activity of aronorosin. Accordingly a structure-activity relationship carried out by Vijayakumar et al. concluded that the carbonyl at C-8 and the bisoxirane moiety are essential for the antifungal activity. ${ }^{26}$ Aranorosin has also been reported to inhibit the antiapoptotic functions regulated by $\mathrm{Bcl}-2 .^{27}$

Three total syntheses ${ }^{28}$ have been reported, each of which has used the same method to install the quaternary spiro stereocentre i.e. an oxidative cyclisation. However, Rama Rao was the first to use (in 1991) the phenolic dearomatisation as a key step to reach the spirolactone backbone $\mathbf{2 4}$ contained in aranorosin (Scheme 9).$^{29}$ Due to the chemical instability of the lactol natural product, the authors chose to prepare the corresponding lactone 24. The quaternary stereocentre was set up via the Wessely-type oxidation of $\mathrm{N}$-trifluoroacetyl-L-tyrosine $\mathbf{2 5}$ in the presence of BTIB and pyridine in acetonitrile. Compound $\mathbf{2 6}$ was obtained in $60 \%$ yield. Deprotection of the Boc group followed by the introduction of the side chain 27 and subsequent epoxidation provided the bis-epoxide 24. Even though the NMR spectra were similar to that reported for the natural compound 22a, the stereochemistry at C-6' could not be firmly established due to the lack of optical rotation data for the side chain.

En route to their total synthesis, both Wipf and McKillop prepared the natural product and its C- $6^{\prime}$ epimer in order to be able to assign its absolute configuration as $R$.

More recently, in a related example, Takagi and co-workers ${ }^{30}$ were able to take advantage of the diastereoselective formation of the spiro quaternary centre during the phenolic

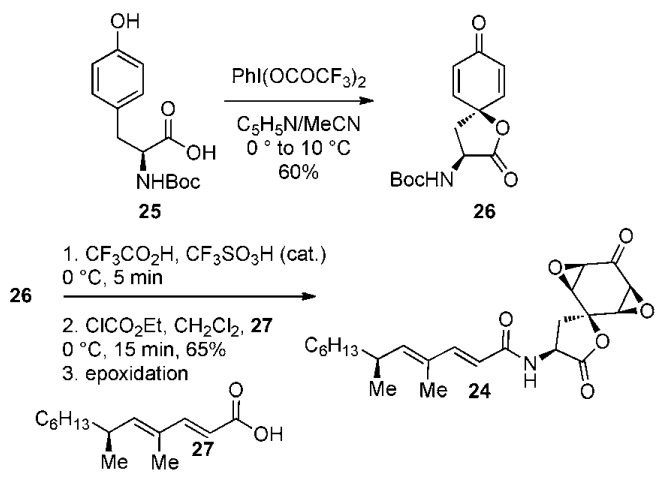

Scheme 9 dearomatisation step leading to $\mathbf{2 8}$ in their total synthesis of (+)-scyphostatin (23) (Scheme 10). This natural product was isolated from a mycelial extract of Dasyscyphus mollissimus SANK-13892, and displays the most potent and specific inhibitory activity to sphingomyelinase (N-SMase) reported to date, with an $\mathrm{IC}_{50}$ of $10 \mu \mathrm{M}^{31}{ }^{31}(+)$-Scyphostatin 23 and its analogues quickly attracted the attention of the synthetic community, ${ }^{32}$ and hold significant potential as drug candidates for the treatment of inflammatory, immunological and neurological disorders.

Structurally, (+)-scyphostatin consists of an oxygenated cyclohexenone adorned with an epoxide and an unsaturated fatty acid side chain bearing an amino alcohol. The tertiary alcohol at C-4 was installed in an efficient manner through reductive opening of the spirolactone 29, to provide the corresponding diol 30 in an excellent yield of $94 \%$. According to Giannis and Pitsinos, ${ }^{32 h}$ the epoxycyclohexenone appears to be important for the biological activity.

\subsection{CAN oxidative coupling}

In $2005,{ }^{16}$ a publication featuring a cerium(Iv)-mediated oxidative coupling of 2,6-dibromophenol derivatives was reported by Kobayashi. None of the classical oxidants usually used for phenolic oxidation were able to deliver the expected compound 31 - reagents derived from iron(III), thallium(III) or lead(IV) led to the degradation of the starting material. Hypervalent iodine(III) BTIB gave only trace amounts of the desired adduct. However cerium(IV) ammonium nitrate (CAN) in aqueous acetonitrile afforded the desired cyclic carbamate in 53\% yield (Scheme 11). This domino reaction allowed the formation of two new $\mathrm{C}-\mathrm{O}$

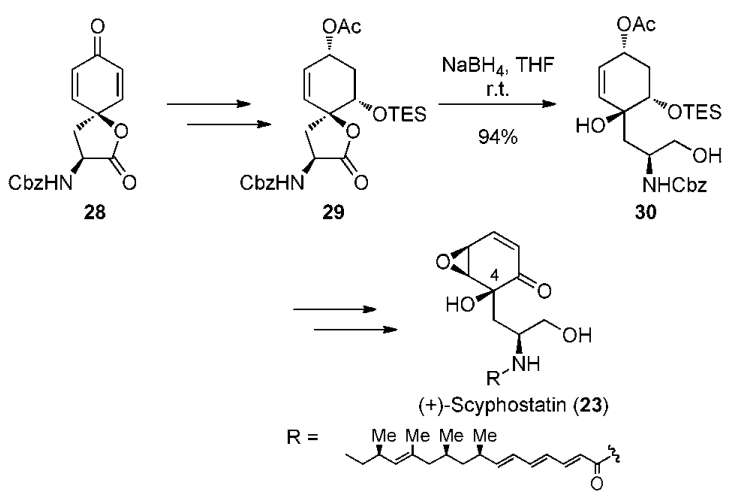

Scheme 10

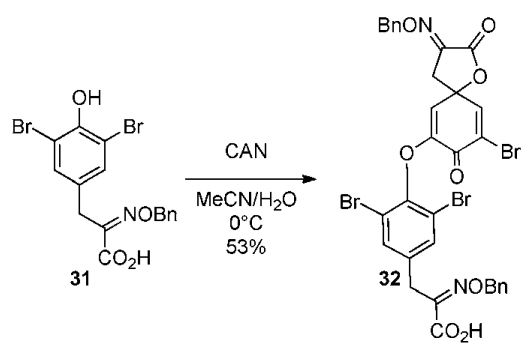

Scheme 11 
single bonds concomitantly with the creation of a stereogenic quaternary centre.

These different approaches illustrate the versatility of phenol ring oxidation to the corresponding quinone in the synthesis of complex molecules. Not only is the diastereoselectivity excellent in many cases, but the conditions for hypervalent iodine(III) are especially mild. Thanks to recent work from Kita, only a catalytic amount of iodotoluene is sufficient to perform the reaction. In addition, chiral hypervalent iodine(III) catalysts reported by Ishihara and Kita are also available for the enantioselective synthesis of these spiro compounds. However, this is only applicable to the chemistry of phenol rings.

\section{Reductive cross-coupling}

A particularly attractive method for the formation of spirolactones was independently reported by Fukuzawa ${ }^{33}$ and Inanaga, ${ }^{34}$ involving the samarium(II)-mediated reductive cross-coupling of ketones with $\alpha, \beta$-unsaturated esters, leading to lactones of type $\mathbf{3 4}$ (Scheme 12). This one-pot reaction effected rapid (1 min) formation of two single bonds and the creation of a quaternary stereocentre in high yields $(95 \%)$, albeit with modest diastereoselectivity. Significant rate enhancement and improved diastereoselectivity was observed with HMPA as co-solvent (entry 1).

This methodology was employed in the first synthesis of lycoperdic acid (35) (Scheme 13), ${ }^{35}$ a non-proteinogenic $\alpha$-amino acid isolated in 1978 from the mushroom Lycoperdon perlatum. ${ }^{36}$ To date, no biological activity has been reported for this natural product. However it is a glutamate derivative and was therefore considered to be promising in the search for new biologically active compounds targeting neurodegenerative disorders. The structural features of lycoperdic acid were determined by both chemical and spectroscopic methods. This five-membered lactone incorporates a quaternary carbon $\alpha$ to the lactone oxygen, which was introduced by the cross-coupling of ketone 36 with methyl acrylate. The corresponding spirolactone $\mathbf{3 7}$ was obtained as a mixture of two diastereomers. Subsequent oxidation provided the amides 38, which could be separated by flash chromatography on silica gel. The major stereoisomer $\mathbf{3 8 b}$ underwent a straightforward hydrolysis in acidic conditions to provide the natural product $\mathbf{3 5}$. The quaternary centre thus established corresponds to the fused stereocentre of the previous spiro compound.

The scope of this reductive cross-coupling reaction was further extended when Merlic developed an enantioselective version

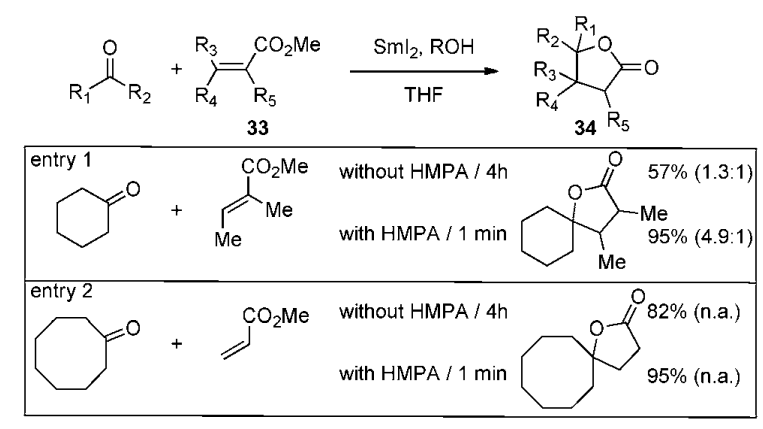

Scheme 12

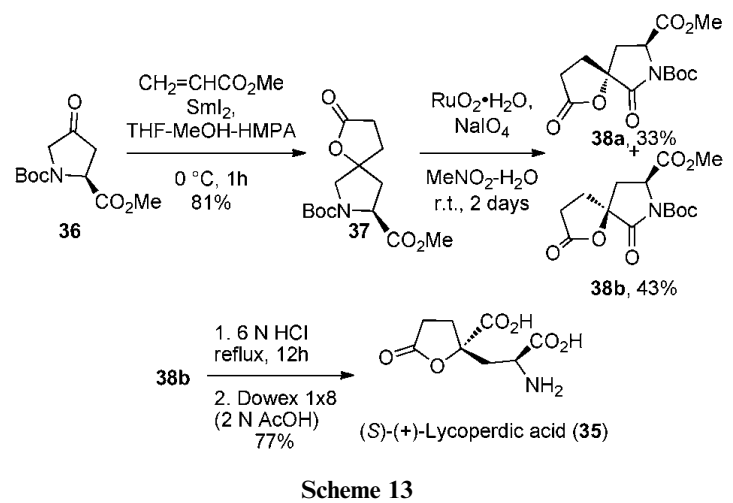

employing enantiopure tricarbonylchromium-arene complexes such as $(S)-39 .^{37}$ Treatment with 2.5 equivalents of samarium iodide and 5 equivalents of methyl acrylate in the presence of tert-butyl alcohol led to the endo-lactone complex $(S, S)-\mathbf{4 0}$ in $81 \%$ yield, with $100 \%$ de and $100 \%$ ee (Scheme 14). The stereocontrol in this process derives from approach of the ester to the ketyl radical anti to chromium. Decomplexation by treatment with iodine provided the enantiopure spiro product $(S)-\mathbf{4 1}$ in $61 \%$ yield.

The authors were then able to access the alternative diastereomer of chromium-spirolactone $(S, R)-\mathbf{4 0}$ via a Lewis acidmediated cationic rearrangement. In presence of 0.5 equivalents of $\mathrm{BF}_{3} \cdot \mathrm{Et}_{2} \mathrm{O}$ in 1,2-dichloroethane for $1 \mathrm{~min}$, the endo-lactone complex underwent a ring-opening-ring-closing sequence via the stabilised carbocation $\mathbf{4 2}$, leading to a mixture of exo- and endolactone $(S, R)-\mathbf{4 0}$ and $(S, S)-\mathbf{4 0}$ in an $8: 1$ ratio. Decomplexation of the major diastereomer $(S, R)-\mathbf{4 0}$ provided the enantiopure spiro product $(R)-\mathbf{4 1}$ in $97 \%$ yield.

Thus, both possible spirolactone enantiomers can be accessed from the same starting material. However, the nature of the substrates is limited due to the requirement for an appended benzene ring.

\section{Radical-based approaches}

Various radical initiators, e.g. TTMSH/AIBN and $\left(\mathrm{Bu}_{3} \mathrm{Sn}\right)_{2} / h \nu$, have been used to synthesise spirolactones. However, all the

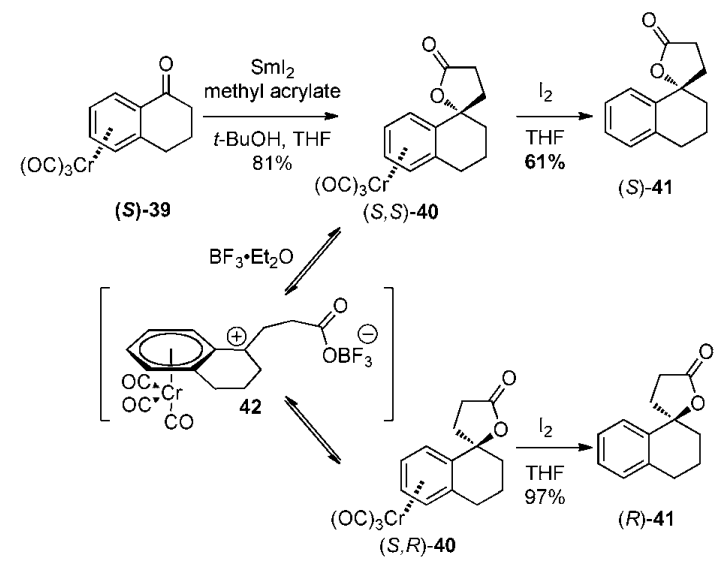

Scheme 14 
different methods rely on the same strategy, which consists of radical-promoted formation of the five-membered lactone (the appended ring at the spiro centre being established already).

A radical-mediated Michael addition was developed by Zhang for the formation of benzospirolactones. ${ }^{38}$ Tris(trimethylsilyl)silane (TTMSH) and a catalytic amount of $2,2^{\prime}$ azobis(2-methylpropionitrile) (AIBN) as initiator were employed to generate the aryl radical from $43\left(\mathrm{X}=\mathrm{CH}_{2}\right)$, which then underwent a smooth 5-exo cyclisation to generate spirolactones 44 in good yield (Scheme 15). This method is quite versatile and tolerant of different substituents on the aryl moiety; similar results were obtained with electron-withdrawing or electrondonating substituents. However, the diastereoselectivity observed is often poor. This approach was then extended to the formation of spirodilactones $(\mathrm{X}=\mathrm{O})$, spirolactone-lactams $(\mathrm{X}=$ $\mathrm{NR})$ and spirolactone-thiolactones $(\mathrm{X}=\mathrm{S})$ in similar yields. ${ }^{39}$

The methodology was exploited in a domino reaction leading to bridged spirolactones after a double cyclisation (Scheme 16) ${ }^{40}$ Generation of the alkyl radical $\mathbf{4 5}$ from bromide $\mathbf{4 6}$ initiated a 5exo cyclisation onto the appended enone to provide a second radical $\mathbf{4 7}$, which could then undergo a second 5-exo-trig cyclisation to generate the bridged lactone $\mathbf{4 8}$ in $78 \%$ yield as a $1: 2$ mixture of diastereomers (Scheme 16). Isolation of compound $\mathbf{4 8}$ suggested that the initial radical added onto the enone anti to the allylic group 45. However, due to free rotation around the allylic double bond the second cyclisation is less selective, explaining the poor diastereoselectivity observed during this sequence. Despite this, three new contiguous stereocentres were created, including the spiro carbon along with two single bonds, making it a very powerful process for building molecular complexity.

Larger ring sizes could also be accessed via this method. When a methyl group is added to the double bond on the side chain (as

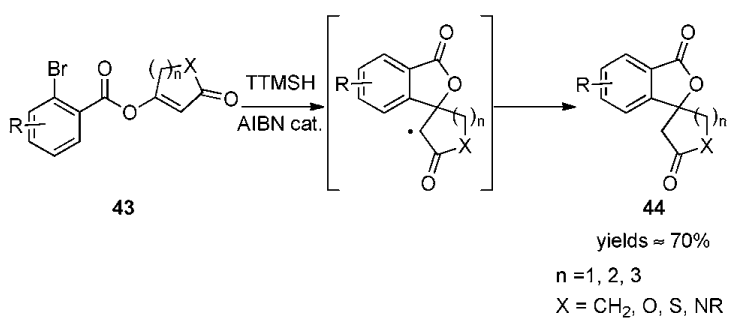

Scheme 15
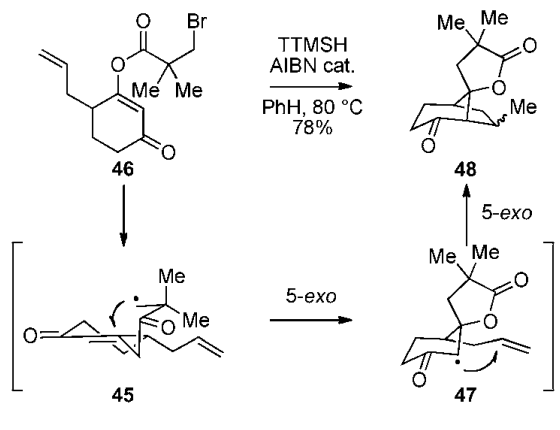

Scheme 16 in 49 and 50), a 6-endo process occurred, affording $\mathbf{5 1}$ and $\mathbf{5 2}$ in 76 and 58\% yield (respectively) as single isomers (Scheme 17). $16 \%$ of the product 53 arising from a single Michael addition was also isolated.

Another method utilised hexabutylditin as the radical initiator. Curran et al. have demonstrated formation of spirolactones via a one-pot atom-transfer addition and annulation of iodomalonate $\mathbf{5 4}$ and methylenecyclohexane (55) in the presence of a catalytic amount of hexabutylditin $(10 \mathrm{~mol} \%)$ under irradiation ( $275 \mathrm{~W}$ sun-lamp). ${ }^{41}$ The reaction is thought to proceed via intermediate $\mathbf{5 6}$ to afford the corresponding lactone $\mathbf{5 7}$ in $47 \%$ yield, together with $25 \%$ of eliminated alkenes $\mathbf{5 8}(8: 1$ endo:exo $)$ (Scheme 18). During this process, several bonds were created sequentially with concomitant formation of the fused quaternary carbon.

\section{Furanyl dienolate-based cyclisation}

Access to spirolactones has also been achieved via the intramolecular alkylation $(\mathrm{X}=\mathrm{I})$ or acylation $(\mathrm{X}=$ imines or aldehydes) of furanyl dienolates of type $\mathbf{5 9}$ (Scheme 19). Once again, this allows simultaneous generation of the quaternary spiro centre and the ring appended to the lactone.

Unlike the classical esterification strategy to form spirolactones bicyclic compounds, in Suginome's approach, the cycle appended to the lactone ring was formed last. ${ }^{42}$

\subsection{Alkylation}

$\gamma$-Deprotonation of benzylic lactone $\mathbf{6 1}$ with LDA in HMPA/ THF generated the corresponding lithium anion, which
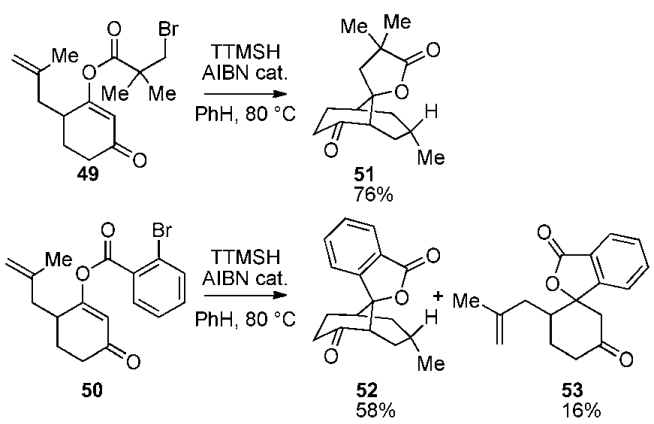

Scheme 17

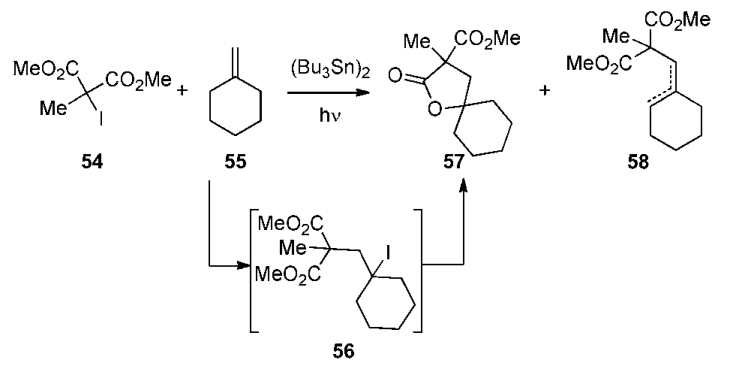

Scheme 18 


$$
\begin{aligned}
& {\left[\mathrm{C}_{\mathrm{O}^{2}} \lambda_{0^{-}}\right] \longrightarrow \mathrm{O}_{0} \lambda_{0}}
\end{aligned}
$$

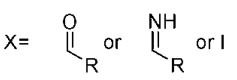

underwent rapid 5- or 6-exo-tet alkylation to provide the spiro products 62a and 62b in 67 and 59\% respectively (Scheme 20).

This process has been extended by Markó to an intermolecular, two-step approach to spirocyclic butenolides. ${ }^{43}$ First, a $\mathrm{ZnCl}_{2}$-mediated condensation of 2-(trimethylsilyloxy)furan (63) and orthoester iodides 64 gave the lactones $\mathbf{6 5}$ in 95 and 83\% yield respectively (Scheme 21). Further treatment with a base produced the corresponding dienolate, which then underwent the previously described intramolecular alkylation reaction to afford the spirocyclic moieties $\mathbf{6 6}$ in good yield, whether the extra ring was five- or six-membered. 2-(Trimethylsilyloxy)furan is thus exploited as a dianion equivalent in this short and efficient sequence.

\subsection{Addition onto an imine (vinylogous Mannich)}

The study of the vinylogous Mannich reaction for the formation of spirolactones has been ably illustrated by the total synthesis of rugolovasines $\mathrm{A}(67 \mathrm{a})$ and $\mathrm{B}(67 \mathrm{~b})$, and croomine (68).

Isolation of rugulovasines A and B was first reported from strains of Penicillium concavo-rugulosium ${ }^{44}$ and subsequently from Penicillium islandicum, ${ }^{45}$ Penicillium biforme ${ }^{46}$ and Penicillium variabile $1912 .{ }^{47}$ Rugolavasines A and B are members of the ergot indole alkaloid family, ${ }^{48}$ which are characterised by the unique spirolactone they contain (Scheme 22). The tetracyclic structure of rugulovasine was proposed on the basis of chemical evidence and crystallographic analysis. ${ }^{49}$ Interestingly, rugulovasines $\mathrm{A}$ and $\mathrm{B}$ were isolated as racemates which interconverted upon warming, presumably via a retro-vinylogous Mannichvinylogous Mannich process. This provided the inspiration for Martin's total synthesis. ${ }^{50}$ The furyl stannane $\mathbf{6 9}$ and the bromo

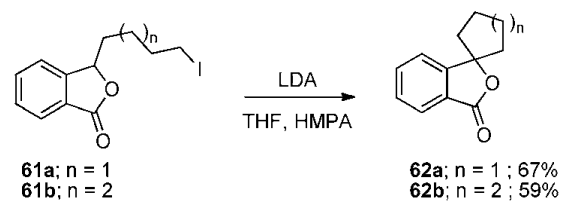

Scheme 20

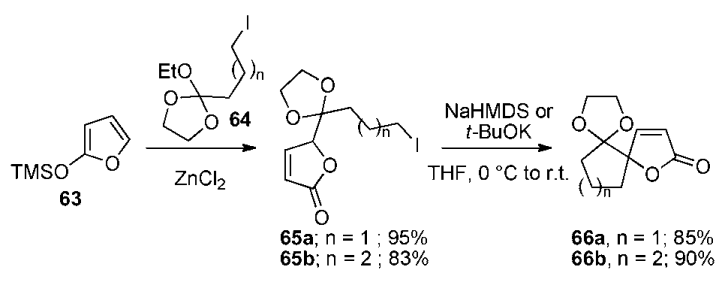

Scheme 21 indole 70 were coupled and advanced to the key cyclisation precursor 71. Reduction of the nitrile group of $\mathbf{7 1}$ with DIBAL-H afforded the intermediate imine 72, which upon treatment with silica underwent the vinylogous intramolecular Mannich reaction and provided the tetracyclic core of the rugolavasines, $\mathbf{7 3}$.

In a very similar fashion, the vinylogous Mannich strategy was applied to the synthesis of $(+)$-croomine and allowed the formation of the seven-membered aza ring. ${ }^{51}(+)$-Croomine, which belongs to the Stemona alkaloid family, was isolated from the roots and rhizomes of Croomia heterosepala in 1979, ${ }^{52}$ and subsequently from Stemona tuberosa ${ }^{53}$ Stemona japonica, ${ }^{54}$ and Stichoneuros calcicola ${ }^{55}$ (Scheme 23). These plants have been applied in traditional Chinese medicine for centuries for the treatment of various respiratory diseases (bronchitis, pertussis and tuberculosis), and to prevent attack by human and cattle parasites, agricultural pests and domestic insects. ${ }^{56}$ The antitussive profile of $(+)$-croomine was highlighted in 2008 , and the natural product was reported to exhibit dose-dependent inhibition of coughing $\left(\mathrm{ID}_{50}=0.18 \mathrm{mmol} \mathrm{kg}{ }^{-1}\right) .{ }^{57}$ Its structure and relative and absolute stereochemistry was elucidated unambiguously on the basis of X-ray crystallographic analysis, and chemical and spectral evidence. ${ }^{52}$ More recently, a biogenetic origin of croomine was suggested and supported by the coisolation of pandanamine from Stichoneuros calcicola. ${ }^{55}$ $(+)$-Croomine is presumably formed by cyclisation of pandanamine (74).
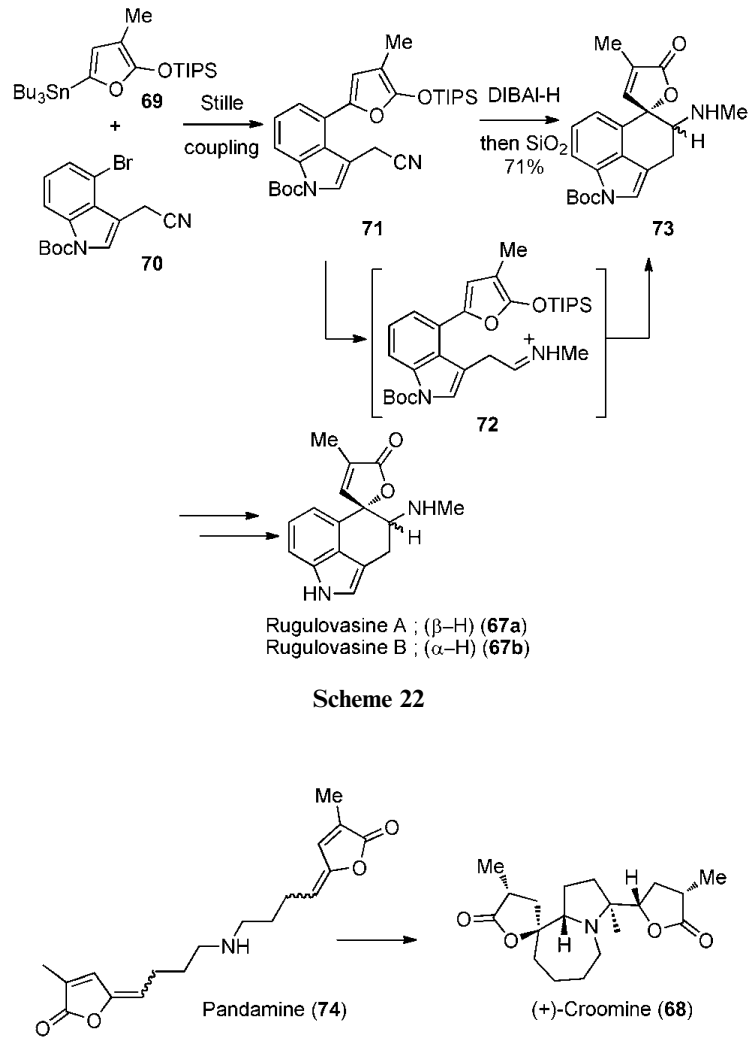

Scheme 23 


\subsection{Vinylogous aldol reaction}

As part of the total synthesis of molecules from the family of the stemonamides and the lambertellols, a vinylogous aldol reaction was employed to form the quaternary spiro centre.

(a) Synthesis of $( \pm)$-stemonamide and $( \pm)$-isostemonamide. $( \pm)$-Stemonamide (75a) and $( \pm$ )-isostemonamide (75b), members of the aforementioned structurally related family of Stemona alkaloids, were isolated from the roots of Stemona japonica by $\mathrm{Xu}$ and co-workers (Scheme 24). ${ }^{58}$ The densely functionalised pyrrolo[1,2- $a$ ]azepine structure of these natural products was elucidated by means of X-ray analysis and extensive NMR spectroscopic analysis. In 2010, two stemonamide analogues were identified that inhibited Pim-3 kinase activities $\left(\mathrm{IC}_{50}=78\right.$ $\mu \mathrm{M}$ for $\mathrm{T}-2 / \mathrm{IC}_{50}=92 \mu \mathrm{M}$ for $\left.\mathrm{T}-5\right)$. In addition, they inhibited the cell proliferation of various cancer cell lines (human pancreatic, hepatocellular and colon cancer) in vitro, ${ }^{59}$ and induced the apoptosis of human pancreatic cancer cell lines in vitro (Fig. 4) ${ }^{60}$ These molecules could therefore be potential potent anticancer drugs with apoptosis-inducing ability.

In 2001, Kende and co-workers reported the synthesis of stemonamide (75a) and its epimer isostemonamide (75b). ${ }^{61}$ Their strategy suggested reaching the spirobicyclic butenolide $\mathbf{7 6}$ via an intramolecular vinylogous aldol reaction from 77 . The bicyclic starting material necessary for this transformation comes from an intermolecular vinylogous Mukaiyama aldol-type reaction between the key subunits $\mathbf{7 8}$ and $\mathbf{7 9}$.

Oxidation of the primary alcohol 77 into aldehyde was performed under Swern conditions. Next, treatment with DBU in dichloromethane at room temperature overnight resulted in the formation of the spiro quaternary centre as a $1: 1$ mixture of diastereomers 76. Finally, the azepine ring $\mathbf{7 5}$ was formed via an
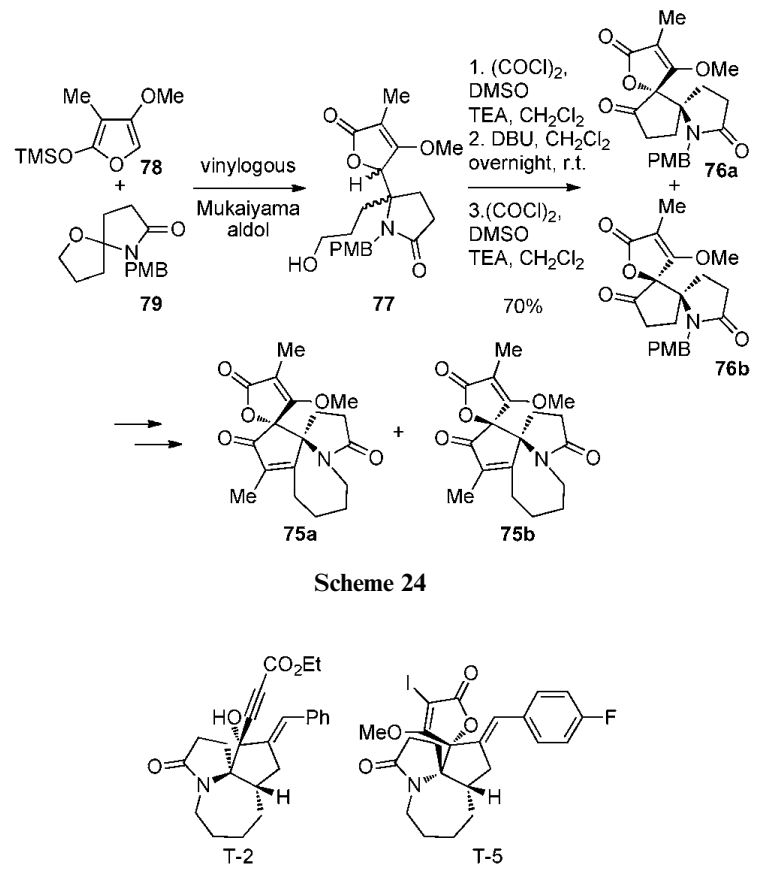

Fig. 4 intramolecular nucleophilic displacement of mesylate in $70 \%$ yield over three steps. Notably, the lack of diastereoselectivity observed during the key spirocyclisation was advantageous, as both epimers were required for the total synthesis of $( \pm)$-stemonamide (75a) and $( \pm$ )-isostemonamide (75b).

(b) Synthesis of lambertellols. The tricyclic spirobutenolides lambertellols $\mathrm{A}, \mathrm{B}^{62}$ and $\mathrm{C}^{63}$ were isolated from the culture broth of a congeneric fungus, Lambertella sp. 1346 (Fig. 5), and are responsible for mycoparasitism on apple fruits. ${ }^{64}$ Structurally, these three molecules present a spiro-1-furan-2-(5H) skeleton which was established by extensive NMR spectroscopic methods. The absolute stereochemistry of lambertellols A and B were determined on the basis of $\mathrm{CD}$ spectra after chemical derivatization. In contrast, lambertellol $\mathrm{C}$ was found to exist as a racemate. A biosynthetic pathway was suggested and supported by the co-isolation of lambertellin and chrysophanol. ${ }^{63,64 b}$ From a biological point of view, lambertellols $\mathrm{A}$ and $\mathrm{B}$ demonstrated growth inhibition of spores of Cochlibolus miyabeanus $\left(\mathrm{IC}_{50}=\right.$ $0.5 \mu \mathrm{g} \mathrm{L}^{-1}$ ) and were found to possess weak cytotoxicity against P388 murine leukemia $\left(\mathrm{IC}_{50}=12\right.$ and $15 \mu \mathrm{g} \mathrm{L}{ }^{-1}$ respectively) ${ }^{65}$

Hashimoto et al. exploited an intramolecular vinylogous aldol reaction to form the spirobutenolide moiety. ${ }^{65}$ Accordingly, methacrylation of $\mathbf{8 1}$ followed by ring-closing metathesis (RCM) with Grubbs II catalyst conveniently provided the requisite butenolide 82 (Scheme 25). The crucial aldol reaction ensued upon treatment of aldehyde $\mathbf{8 2}$ with NaHMDS in DMF at $-40{ }^{\circ} \mathrm{C}$, forming the lambertellol ring within 83a and its diastereomer 83b in 77 and $13 \%$ yield respectively. Once again, both diastereomers could be advanced to their respective natural products lambertellol B and A after late-stage chemoselective oxidations. Lambertellol $\mathrm{C}$ was obtained by simple oxidation of the corresponding diol.

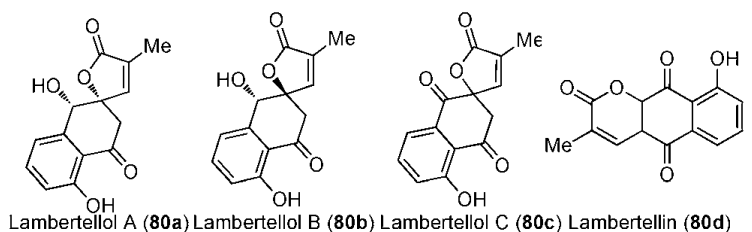

Fig. 5
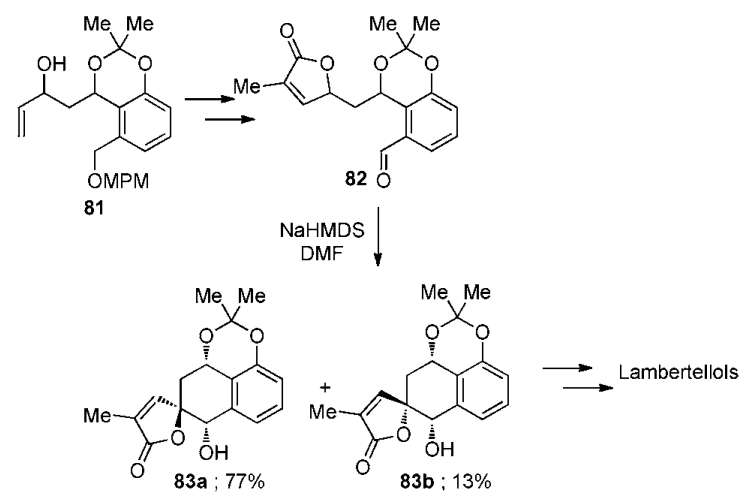

Scheme 25 
Interestingly, employing the sterically congested butenolide $\mathbf{8 4}$ allowed adjustment of the diastereoselectivity of the reaction in favour of diastereomer 85a (2.2:1 dr) (Scheme 26).

\section{Cationic rearrangement}

During the course of studies to delineate the biomimetic pathway from dehydrocurdione 86 to curcumenol 87 and isocurcumenol 88, Kodama and Fukazawa showed that, whilst dehydrocurdione afforded curcumenol upon treatment with potassium carbonate or alumina in benzene, when dehydrocurdione was treated under acidic conditions, a $1: 1$ diastereomeric mixture of spirolactone $\mathbf{8 9}$ was obtained quantitatively (Scheme 27). ${ }^{66}$ This interesting transformation presumably proceeds via the described cationic intermediate $\mathbf{9 0}$ rather than the pericyclic (Alder-ene) pathway to $\mathbf{8 7}$ and $\mathbf{8 8}$.

Another cationic rearrangement, this time involving an arylnitrenium ion, has been highlighted. A solution of $\beta$-(4-azidophenyl)propanoic acid in trifluoroacetic acid at $0{ }^{\circ} \mathrm{C}$ was treated with trifluoromethanesulfonic acid and allowed to stir at room temperature for $25 \mathrm{~h}$ (Scheme 28). ${ }^{67}$ The spirodienone 92 resulted from ipso-attack by the carboxy group para to the nitrenium ion, but 92 was produced in a low yield of $20 \%$.

Another method utilising allylic cations has also been employed to generate spirolactones. Treatment of allylic alcohol 93 with hydrochloric acid provided the stabilised allylic carbocation 94 (Scheme 29), ${ }^{68}$ which was trapped by the tethered

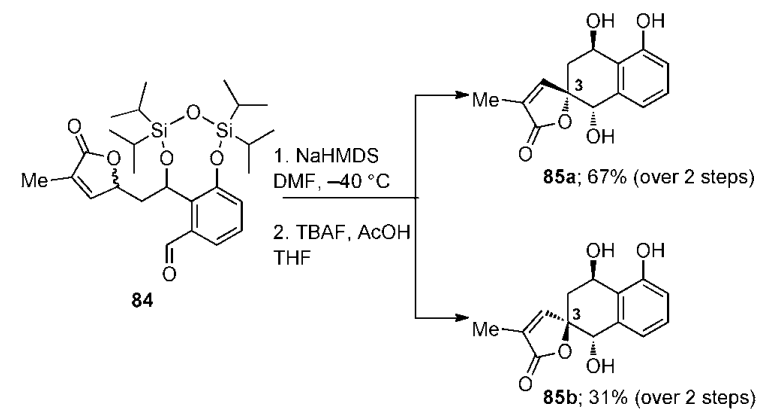

Scheme 26
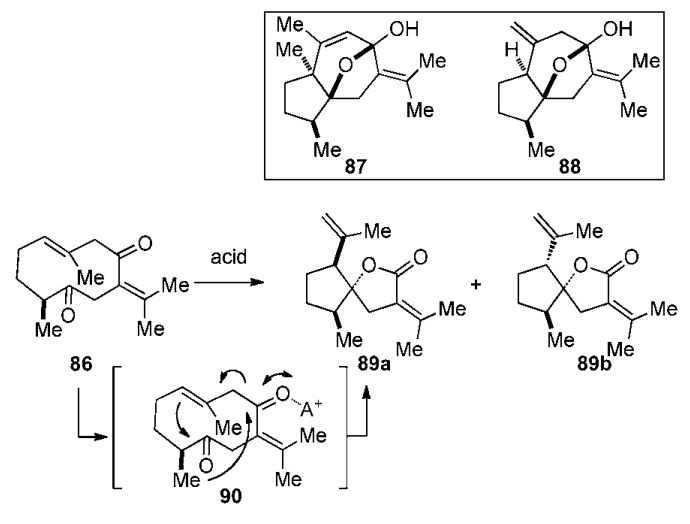

Scheme 27

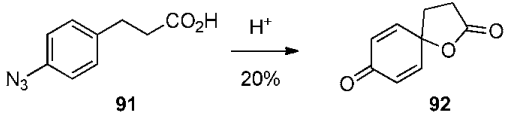

Scheme 28

carbonyl group to provide the allylic spirolactone $\mathbf{9 5}$ in good yield $(67 \%)$.

\section{Use of organometallic derivatives}

In the following section, we provide an inventory of the reactions that use organometallic species to access spirolactones. Three main reactions have been reported in the literature: double acylation using bis-metallated species, metal-mediated Reformatsky reaction, and processes involving carbonyl insertion.

\subsection{Double acylation}

Bis-metallated species have been exploited to form spirocyclic molecules in a single step through annulation to a carbonyl substrate. This is exemplified by Canonne strategy, which consists of adding a bis-Grignard reagent 96 to a cyclic carbonyl 97. ${ }^{69} \mathrm{~A}$ double acylation took place on the same carbonyl of an anhydride derivative, and afforded the corresponding spirolactones 98 (Scheme 30). This strategy has the advantage of flexibility over the bonds formed during the annulation process, as exemplified by addition of lithium 3-lithiopropanoate to cyclic ketone 99 (Scheme 31).

A related strategy reported by Santelli and co-workers ${ }^{70}$ involves the double Sakurai addition of 1,8-bis(trimethylsilyl)octa-1,6-diene 101 with succinic anhydride (Scheme 32), to generate spirolactone $\mathbf{1 0 2}$ in good yield $(80 \%)$. However, this

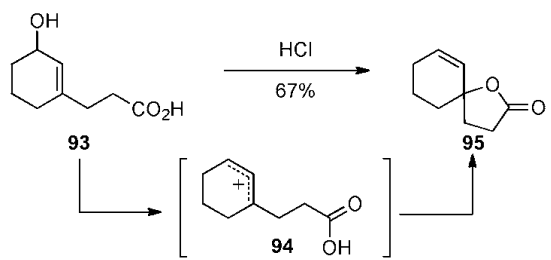

Scheme 29

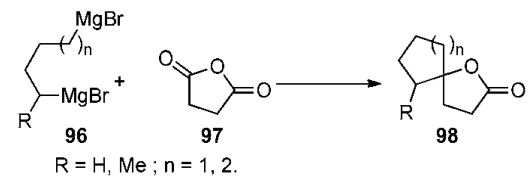

Scheme 30

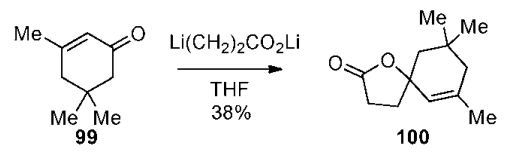

Scheme 31 
procedure is less efficient with $\alpha, \beta$-unsaturated anhydrides like maleic or itaconic anhydride. Divinylspirolactones $\mathbf{1 0 2}$ have proven to be useful in the synthesis of a number of natural and non-natural steroids. ${ }^{70}$

\subsection{Reformatsky-type reaction}

A coupling reaction catalysed by $\mathrm{SmI}_{2} / \mathrm{NiI}_{2}$ and using $\beta$-propiolactone (103) as the reactant has been described to provide spirolactones of different size $104(0 \leq n \leq 3)$ in good yields (from 76 to $85 \%$ yield) (Scheme 33).$^{71}$ During the course of this reaction, samarium mediated the formation of a homoenolate equivalent 106, which then reacted with a cycloalkanone. A samarium-mediated spirocyclisation of cycloalkanones with methyl 3-bromopropionate had already been reported by Csuk seven years earlier, ${ }^{72}$ but the spirolactone product was isolated only as a minor product of the reaction. Since then, several groups have shown their interest in this transformation, and it has been the subject of extensive publications: metallic $\mathrm{Zn},{ }^{73} \mathrm{Sn},{ }^{74}$ and $\mathrm{In}^{75}$ derivatives have been reported to mediate reductive cyclisation of bromomethyl acrylate derivatives $\mathbf{1 0 7}$ and cyclic ketones 108 (Scheme 34). This Reformatsky-type reaction provided spirolactones $\mathbf{1 0 9}$ exhibiting an exo double bond in moderate $\left(40 \% \text { for } \mathrm{SnCl}_{2}\right)^{74}$ to good yield $(82 \%$ for electrogenerated $\left.\mathrm{Zn}^{*}\right) .^{73}$

Stereoselective spirolactone formation has been observed in some cases. For example, addition of deoxyuloside 110 to $(Z)$ ethyl 2-(bromomethyl)but-2-enoate and zinc-silver/graphite at $-30{ }^{\circ} \mathrm{C}$ for seven hours provided the spiro compound 111 in $74 \%$ yield as a single diastereomer (Scheme 35). ${ }^{76}$ This could be explained by the highly ordered chair-like transition state 112, in which the $r e$-face of the organozinc intermediate attacks the reface of the carbonyl moiety. The preference for equatorial attack at the $r$-face of the carbonyl group over axial attack may be explained by steric hindrance to $s i$-face approach by the axialoriented anomeric methoxy group.

In a similar fashion, Trivedi has utilised $\alpha$-hydroxy ketones to effect a highly diastereoselective Reformatsky-type reaction

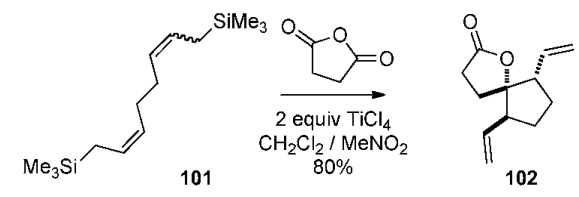

Scheme 32

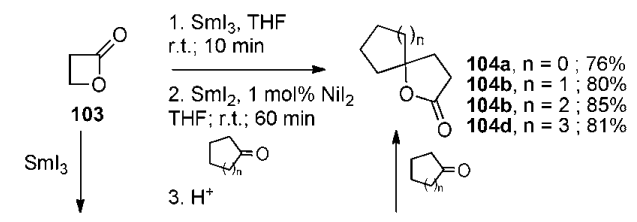

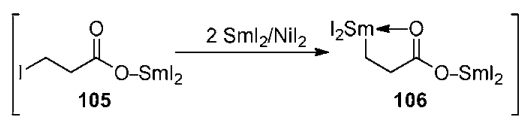

Scheme 33

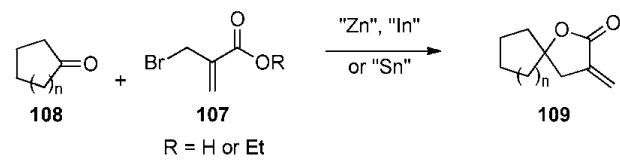

Scheme 34

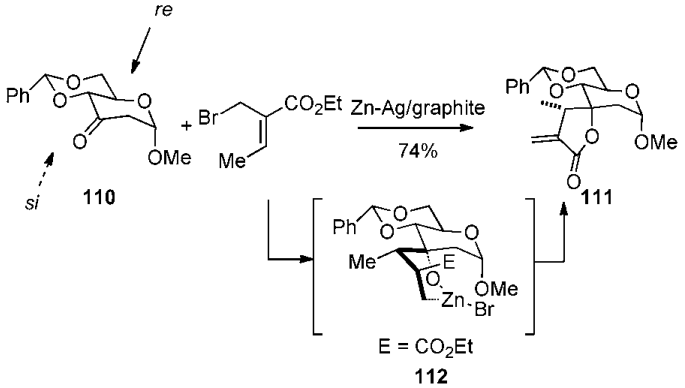

Scheme 35

leading to spiro- $\alpha$-methylene- $\gamma$-butyrolactones (Scheme 36$).{ }^{77}$ Keto steroids incorporating an $\alpha$-hydroxy subsituent 113b afforded the corresponding spirocyclic molecule $\mathbf{1 1 4 b}$ as a single diastereomer, whereas the same experiment onto a precursor lacking this secondary alcohol function 113a led to a $70: 30$ diastereomeric mixture at the spirocentre of 114a. This observation was rationalised by a chelated transition state (Fig. 6) in which the developing carbanion of the Reformatsky reagent attacks from the $r e$-face, the $s i$-face being disfavoured due to repulsion with the lone-pair of the oxygen of the hydroxyl group.

This Reformatsky-type methodology has been utilised for the synthesis of sugar moieties substituted with an $\alpha$-methylene- $\gamma$ lactone, ${ }^{78}$ and as a key step, in the total synthesis of stemospironine (115) by Rauter and co-workers (Scheme 37). ${ }^{79}$ Stemospironine is another Stemona alkaloid that exhibits antiinsecticidal properties, and was isolated from Stemona japonica by Murakoshi and coworkers. ${ }^{80}$ Structurally, the 1-azabicyclo[5.3.0]decane nucleus is embedded in a complex tetracyclic

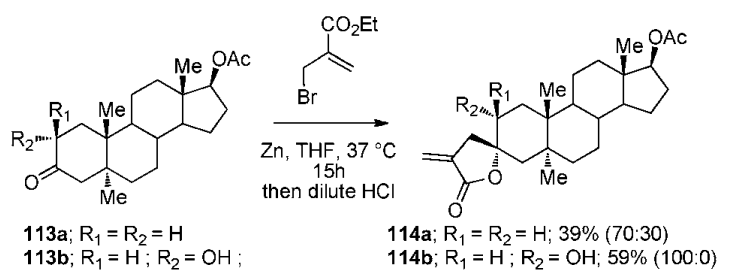

Scheme 36

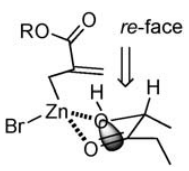

Fig. 6 
scaffold. The relative and absolute configuration were established unambiguously by X-ray crystallographic analysis and spectroscopic methods.

The spirolactone 117 was obtained in $86 \%$ yield with complete facial selectivity after treatment of bicyclic compound $\mathbf{1 1 6}$ with ethyl bromomethylacrylate and zinc dust in THF.

\subsection{Carbonyl insertion}

(a) $\mathrm{Mg}-\mathrm{CO}_{2}$. Rieke and co-workers have utilised a one-pot sequence in which magnesium metallocycle 119 reacted with ketones at $-78^{\circ} \mathrm{C}$ (Scheme 38). The corresponding 1,2-addition adduct $\mathbf{1 2 0}$ then reacted with carbon dioxide, leading to the introduction of the carbonyl group contained in the final lactone. The subsequent lactonisation provided the desired spirocyclic molecule $\mathbf{1 2 2}$ in good yields (from 59 to $68 \%$ depending on the nature of the ketone). ${ }^{81}$

(b) Nickel-catalysed alkoxycarbonylation. Ogoshi and coworkers have exploited the formation of a [4.3]spirolactone starting from a nickel complex. ${ }^{82}$ Oxidative cyclisation of 1,3butadiene and cyclobutanone mediated by a nickel catalyst led to the formation of an $\eta^{3}: \eta^{1}$-allylalkoxynickel complex $\mathbf{1 2 5}$ (Scheme 39). The latter, upon treatment with carbon monoxide, provided the spiro molecule $\mathbf{1 2 6}$ in $38 \%$ yield.

\section{Halolactonisation}

Spiro- $\gamma$-butyrolactones may also be obtained in excellent yield via halolactonisation of enol lactones such as 127 (Scheme 40). ${ }^{83}$ This transformation presumably proceeds via the intermediate bromonium ion $\mathbf{1 2 9}$ and bromo acid $\mathbf{1 3 0}$.

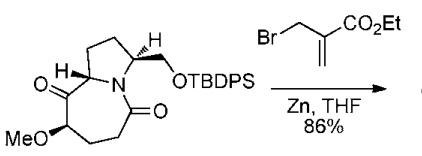

116

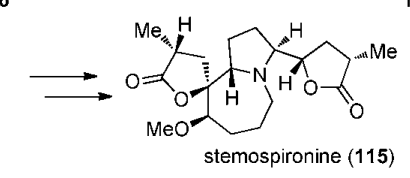

Scheme 37

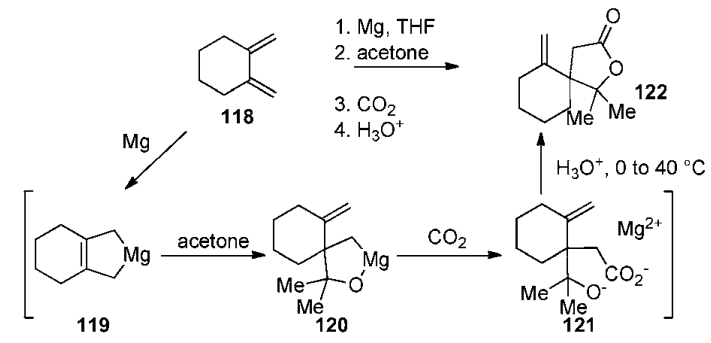

Scheme 38
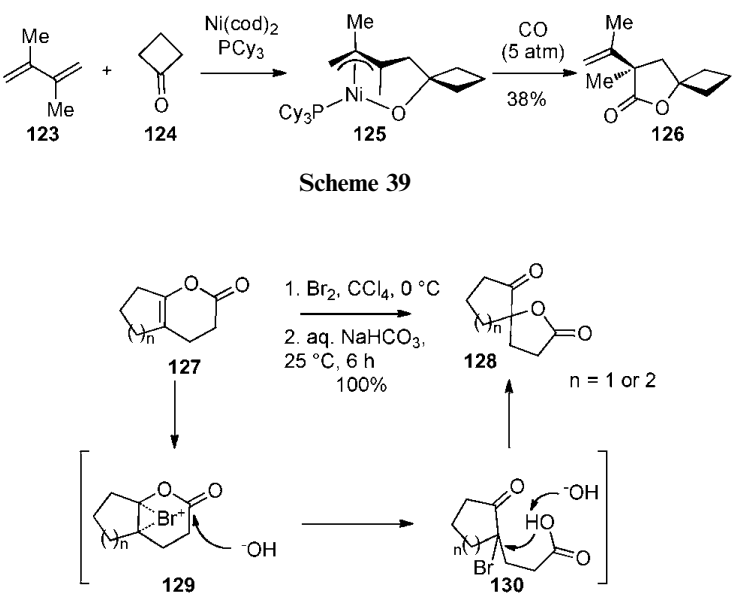

Scheme 40

A similar strategy was adopted by Wawrzeńczyk, who used iodine and $N$-bromosuccinimide on limonene and carane systems respectively ${ }^{84}$ Larock et al. formed the iodonium 132 on a triple bond with $\mathrm{ICl}$ and therefore obtained the corresponding butenolide $\mathbf{1 3 3}$ in a quantitative manner via an ipso-halocyclisation (Scheme 41). ${ }^{85}$ This same reaction may also be promoted by $\mathrm{CuX}$ $(\mathrm{X}=\mathrm{I}, \mathrm{Br}, \mathrm{SCN})$ and a source of electrophilic fluoride, which produced the spirobutenolide in $45 \%$ yield. ${ }^{86}$

Finally, Piva et al. obtained the butyrolactone $\mathbf{1 3 5}$ in $69 \%$ yield through treatment of ethyl 3-cyclobutylprop-2-enoate 134 with in situ-generated TMSI (Scheme 42) ${ }^{87}$ Dihydroxylation of $\mathbf{1 3 4}$ also provided directly the parent $\beta$-hydroxylactone $\mathbf{1 3 6}$ in $69 \%$ yield.

\section{Pericyclic-type reactions}

Pericyclic reactions are without doubt amongst the most powerful of synthetic tools and often offer a high degree of selectivity in both their inter- or intramolecular versions. A further advantage they offer is often providing access to significant complexity from relatively simple precursors. As will be discussed, pericyclic reactions have allowed a convergent, stereoselective and efficient approaches to the spirocyclic molecules, compounds targeted in this review. Here the term pericyclic is

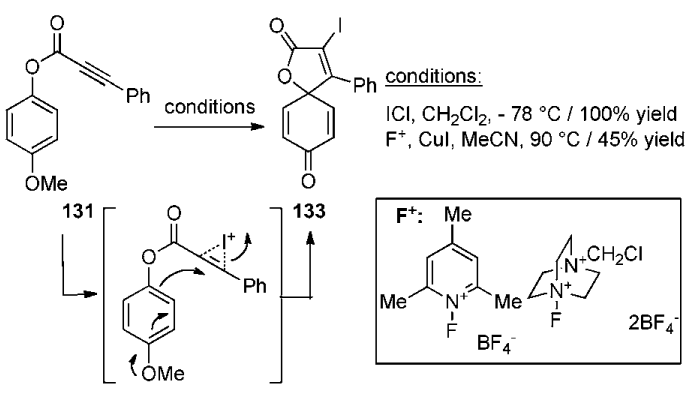

132

Scheme 41 


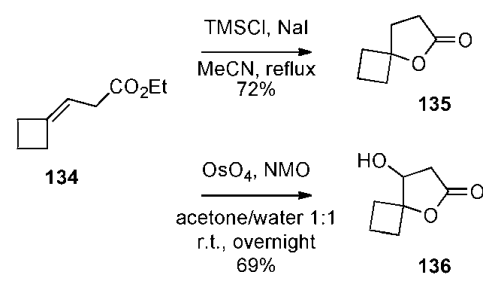

Scheme 42

used loosely to describe those reactions which appear to have arisen through a formal pericyclic process, although mechanistically this may not always be the case.

\subsection{Electrocyclisation}

Access to [4.2]spirolactone $\mathbf{1 3 7}$ was achieved by thermal rearrangement of diazo ketone $\mathbf{1 3 8} .^{\mathbf{8 8}}$ Upon brief heating in refluxing benzene, a Wolff rearrangement occurred, leading to the intermediate ketene 139 (Scheme 43). This stereoselectively provided the spiro compound $\mathbf{1 3 7}$ as a single diastereomer in 50\% yield via a hypothetical ordered dipolar cyclic transition state. This is a rare example of the formation of [4.2]spirolactones.

\section{$9.2[2+1]$ photocycloaddition}

In 1995, Tomioka reported another route to this rare [4.2]spirolactone structure. ${ }^{89}$ Irradiation of a solution of benzocyclobutenedione with $\mathrm{C}_{60}$ in toluene provided spiro $\mathrm{C}_{60}$ monoadduct in $35 \%$ yield, along with multiadducts and $\mathrm{C}_{60}$ starting material $(55 \%)$ (Scheme 44)

\section{$9.3[2+2]$ cycloaddition}

Several cases of dimerisation of alkylidenebutenolides have been reported in the literature, either under photolytic ${ }^{90}$ or thermal conditions. ${ }^{91}$ When acetoxy furanone 142 was heated in a mixture of acetic acid and anhydride acetic with a catalytic amount of sulfuric acid, the corresponding methylene furanone protoanemonin (143) was formed, which immediately dimerised to the natural product anemonin $\mathbf{1 4 4}^{\mathbf{9 2}}$ in $53 \%$ yield (Scheme $45) .{ }^{91}$

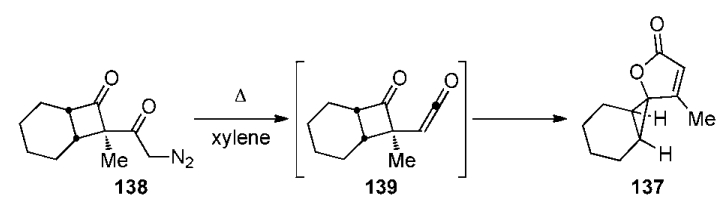

Scheme 43

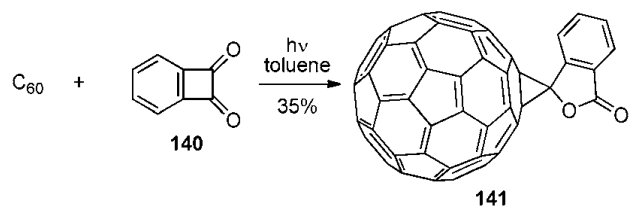

Scheme 44

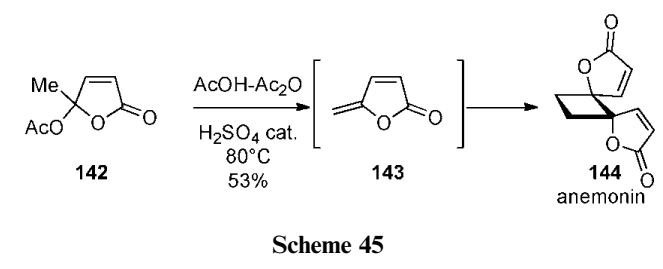

Upon irradiation with a mercury lamp, the bioactive secondary metabolite $(Z)$-ligustilide $\mathbf{1 4 5}$ underwent dimerisation, leading to four different products. The natural product riligustilide 146 and three other phthalides $147 \mathbf{a}-\mathbf{c}$ were isolated in 7,18 , 11 and $7 \%$ yields, respectively (Scheme 46).

More recently, Sulikowski et al. reported the utilisation of the intramolecular $[2+2]$ photocycloaddition in their studies directed towards the total synthesis of bielschowskysin (148) (Scheme 47). ${ }^{90 b}$ This natural product was isolated in 2004 from Pseudopterogorgia kallos and exhibits valuable biological activities, including strong in vitro cytotoxicity against the EKVX non-small-cell lung cancer $\left(\mathrm{GI}_{50}<0.01 \mu \mathrm{M}\right)$ and CAK-1 renal cancer cell lines $\left(\mathrm{GI}_{50}=0.51 \mu \mathrm{M}\right)$, as well as antiplasmodial activity against drug-resistant strains of the malaria-causing protozoan parasite, Plasmodium falciparum $\left(\mathrm{IC}_{50}=10 \mu \mathrm{g}\right.$ $\left.\mathrm{mL}^{-1}\right){ }^{93}$ This highly oxygenated hexacyclic diterpene contains eleven stereocentres and an unusual [4.3]spirolactol moiety. Irradiation of a solution of 149a in acetone first led to the isomerisation of 149a, therefore providing a mixture of geometric isomers of the starting material 149a and 149b. Further irradiation resulted in the conversion of both isomers, providing the tetracyclic core $\mathbf{1 5 0}$ of the target compound in $50 \%$ yield as a mixture of two diastereomers in a $5: 1$ ratio.

\subsection{Diels-Alder reaction}

The Diels-Alder reaction has been used as a powerful tool to generate quaternary stereogenic centres, and in this regard spirolactones are no exception.

(a) Methodology. Participation of the exocyclic double bond of an alkylidene butenolide as a $2 \pi$ partner in an intermolecular Diels-Alder reaction was initially reported by Font in 1986 (Scheme 48).$^{94}$ Upon heating for $20 \mathrm{~h}$ at $210^{\circ} \mathrm{C}$ in the presence of hydroquinone and a large excess of butadiene, compound $\mathbf{1 5 1}$ cyclised to the fused six-membered ring $\mathbf{1 5 2}$ in 53\% yield but

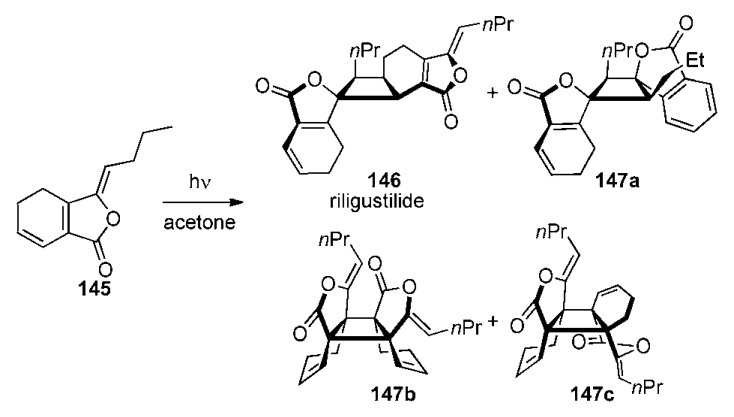

Scheme 46 


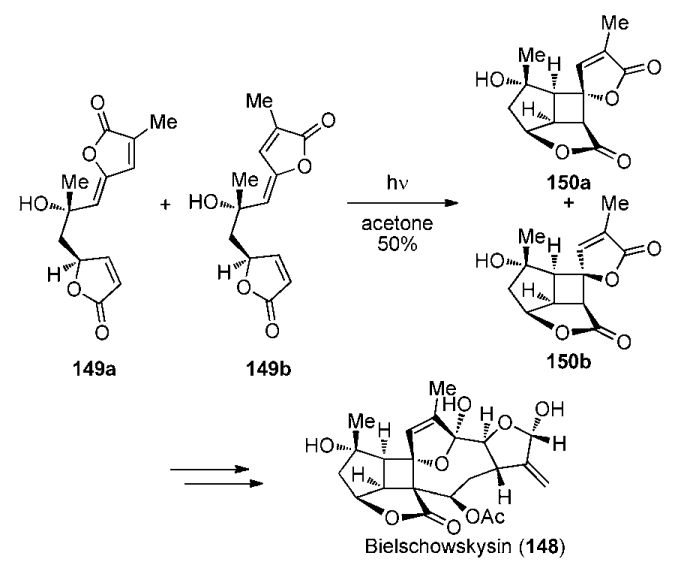

Scheme 47

a side reaction was also noticed. Under the conditions of the reaction, butenolide 151 first eliminated to the corresponding protoanemonin $\mathbf{1 4 3}$. The latter then underwent the [4+2] reaction at the exocyclic double bond, leading to spiro adduct 153 in $25 \%$ yield.

Subsequently, Poss et al. prepared dienophile 154 from L-ascorbic acid, and found that in the presence of various dienes Diels-Alder reactions occurred chemoselectively on the exocyclic double bond of the butenolide (Scheme 49). ${ }^{95}$ After stirring the two partners 154 and 155 in $\mathrm{THF}$ at $125^{\circ} \mathrm{C}$ for three days the spirocyclic adduct 156 was isolated in $54 \%$ yield as a single regioisomer. However no exolendo preference was observed, as evidenced by the diastereomers being isolated in a $1: 1$ ratio. Similar conclusions were independently reached by Yoshii. ${ }^{96}$

From 1990 to 1997 Font and Ortuño carried out extensive research in order to highlight and understand the factors governing the regio-, chemo- and stereoselectivity of this reaction. ${ }^{97}$ The nature of the diene (open-chain $C$-substituted, heterosubstituted, cyclic and asymmetric dienes), dienophile and reaction conditions were studied and theoretical calculations and mechanism investigations were performed.

The dienophile alkylidene butenolide, being a conjugated lactone but also an enol lactone, is a complex captodative system

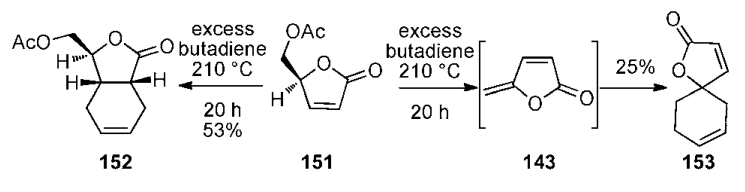

Scheme 48

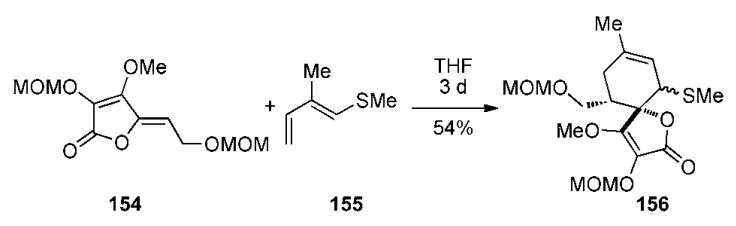

Scheme 49 of activation. Theoretical calculations using MNDO and AM1 semi-empirical methods concluded that the frontier orbital theory failed to predict the chemoselectivity of the transformation, and the authors therefore suggested an asynchronous pathway through a biradicaloid transition state. ${ }^{97 a}$ Cyclobutane derivatives, detected at the initial stage of the reaction, supported this biradical mechanism (Scheme 50). ${ }^{97 e}$ The authors synthesised cyclobutane 157 under photochemical conditions, and this, upon heating to $150{ }^{\circ} \mathrm{C}$, furnished the corresponding [4+2] cycloadduct $\mathbf{1 5 3}$, thus demonstrating that cyclobutane species were intermediates in the formation of the six-membered ring spirolactones.

The synthesis of optically active spiro[4,5]decanes $\mathbf{1 5 9}$ (which are building blocks found in many products of biological importance) via chiral-auxiliary-mediated $[4+2]$ reactions has been demonstrated. ${ }^{98}$ Three different dienes bearing optically active auxiliary groups $158\left(\mathrm{R}^{*}=(-)\right.$-menthyl, $(-)$-bornyl or $(+)$-isocampheyl) were reacted with protoanemonin 143 in a sealed tube between 120 and $140{ }^{\circ} \mathrm{C}$ for 14 to $18 \mathrm{~h}$ in dichloromethane (Scheme 51). Asymmetric induction was observed but, in all cases, four different diastereomers were obtained. However, the diastereofacial selectivity, especially for the (-)-bornyl substituted diene, was reasonable (endo:exo $=$ $28: 72)$.

(b) Synthesis of ircinianin. (-)-Ircinianin $(\mathbf{1 6 0})^{99}$ and its cyclic isomer (+)-wistarin $(\mathbf{1 6 1})^{\mathbf{1 0 0}}$ are unique cyclic furanosesterpenetetronic acids (Fig. 7) isolated from the marine sponge Ircinia wistarii. The structures of these unique molecules were elucidated by X-ray crystallographic analysis (for (-)-ircinianin only) and NMR spectroscopic analysis, although the absolute configurations remained unclear at the time. Uenishi has demonstrated that perchloric acid promoted the cyclisation of (-)-ircinianin to $(+)$-wistarin, therefore highlighting the possible biomimetic pathway to (+)-wistarin. ${ }^{101}$

Yoshii achieved the first total synthesis of racemic ircinianin in $1986 .{ }^{102}$ The key step to form the $(5,6,5)$ core including the spiro quaternary stereocentre involved a biomimetic thermal intramolecular $[4+2]$ reaction (Scheme 52). Accordingly, tetraene 162 was heated in boiling benzene and afforded $( \pm)$-ircinianin in $71 \%$ yield as a single diastereomer.

A decade later, as part of a project devoted to the determination of the absolute configuration of these interesting natural

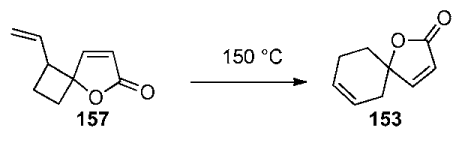

Scheme 50

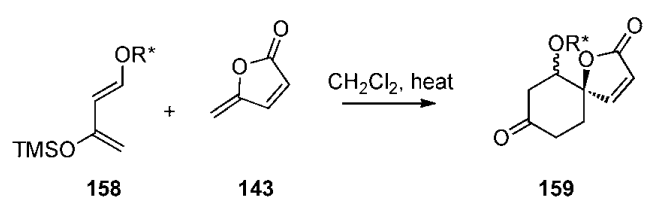

Scheme 51 

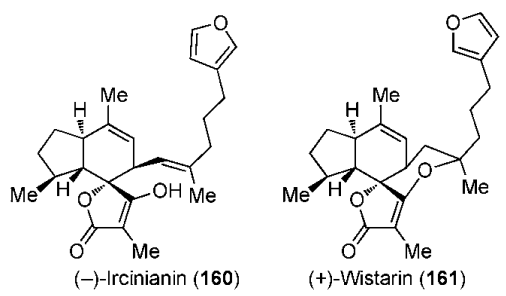

Fig. 7

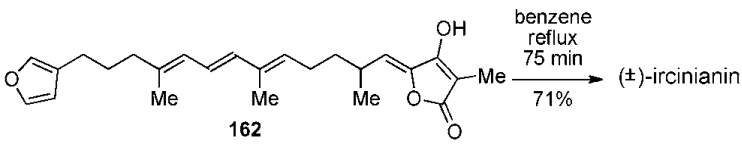

Scheme 52

products, Uenishi et al. developed an enantioselective approach and achieved the first asymmetric total synthesis of (-)-ircinianin. ${ }^{103}$ Their synthetic strategy is outlined in Scheme 53 and relies on the same biomimetic intramolecular Diels-Alder key step as Yoshii. They envisaged that the fully elaborated precursor 163 might be formed by means of a Nozaki-Hiyama-Kishi-Takai reaction (NHKT) between the two subunits 164 and 165 .

Surprisingly, when a solution of compounds 164 and 165 in DMSO were treated with $\mathrm{NiCl}_{2} / \mathrm{CrCl}_{2}$ for $18 \mathrm{~h}$, the isomer $\mathbf{1 6 3 \beta}$ $(\mathrm{OH}=\beta)$ resulting from the NHKT coupling was obtained in $20 \%$ yield, along with $60 \%$ of the cycloadduct resulting from the Diels-Alder reaction, 166 $\alpha$ (Scheme 54). It is noteworthy that the tricyclic structure $166 \alpha$ was obtained as a single diastereomer.

From these experimental results, several conclusions could be made. The chromium(II) chloride probably acts as a Lewis acid catalysing the $[4+2]$ reaction and the $\mathrm{Ni} / \mathrm{Cr}$-mediated coupling

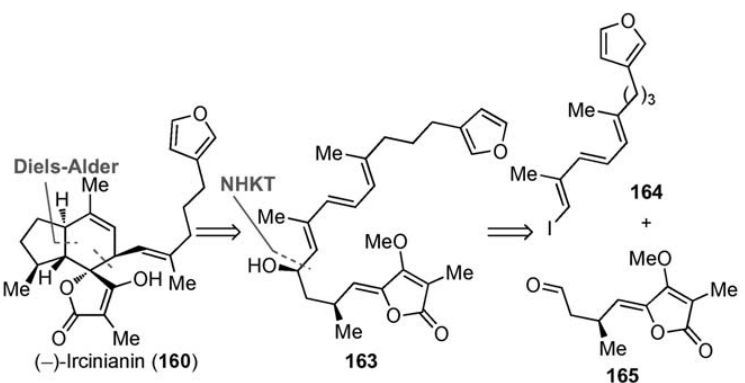

Scheme 53

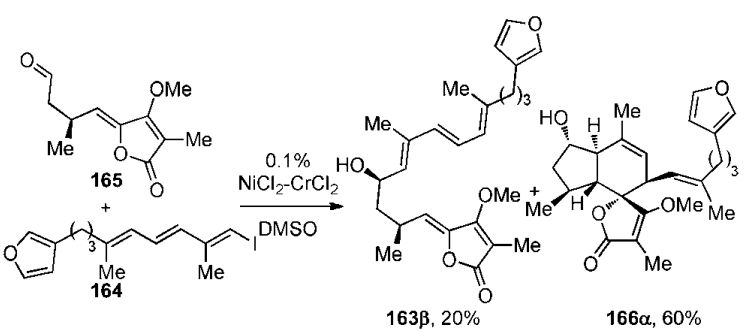

Scheme 54 certainly occurred prior to cyclisation. In addition, the fact that the trans-fused product $163 \alpha$ was preferred over the cis-fused product indicates that $\mathbf{I} \boldsymbol{\alpha}$ is the most likely transition-state (Scheme 55). This last observation might explain why $163 \beta$ failed to give the Diels-Alder cycloadduct $166 \beta$ under the mild reaction conditions. If we assume, by analogy with $163 \alpha$, that I $\beta$ is the most likely transition state, to overcome the steric interaction between the Me group of the diene and the hydroxyl group harsher reaction conditions are required.

In conclusion, the first enantioselective synthesis of (-)-ircinianin and (+)-wistarin has been accomplished featuring the construction of the quaternary spiro centre by a domino reaction involving a metal-mediated coupling followed by a Diels-Alder reaction. The absolute configuration of ircinianin and wistarin has therefore unambiguously been assigned.

(c) Synthesis of abyssomicin. Abyssomicin C (167a), isolated by Süssmuth in $2004^{3}$ from a marine actinomycete, Verrucosispora strain AB18-032, and found to possess significant levels of antimicrobial activity against a variety of Gram-positive bacteria, especially against Staphylococcus aureus strains (MIC against methicillin-resistant $S$. aureus $=4 \mu \mathrm{g} \mathrm{mL}^{-1}$ ) and drug-resistant strains (MIC against vancomycin-resistant $S$. aureus $=13 \mu \mathrm{g}$ $\mathrm{mL}^{-1}$ ) (Fig. 8). Its antibiotic activity is mediated through inhibition of the $p$-aminobenzoic acid pathway. Its chemical structure was determined by comprehensive NMR and MS spectroscopic analysis, and revealed a unique oxabicyclo[2.2.2] octane subunit, a tetronate moiety and an 11-membered ring bearing an enone with an $E$-configured alkene.The stereochemistry of abyssomicin $\mathrm{C}$ was assigned as shown in structure 167a. The co-isolation of inactive compounds abyssomicin B (167b) and D (167c), lacking the $E$-olefin, with abyssomicin $\mathrm{C}$ suggested that the enone might serve as a Michael acceptor in both the mechanism of action and the biogenesis of abyssomicin $\mathrm{B}$ and $\mathrm{D}$.

Because of its intriguing and unusual structural features combined with unique biological activities, abyssomicin $\mathrm{C}$

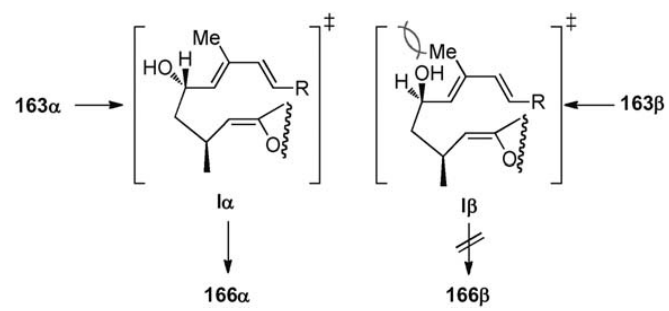

Scheme 55
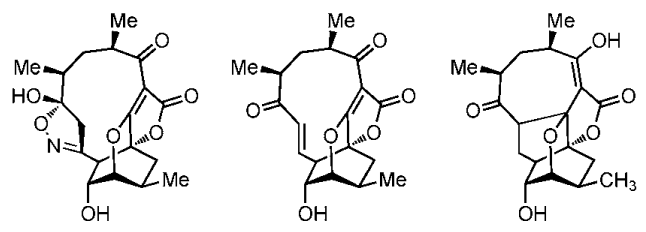

Abyssomycin B (167b) Abyssomycin C (167a) Abyssomycin D (167c)

Fig. 8 
quickly became an attractive challenge for the worldwide synthetic community. ${ }^{104}$ To date, only two total syntheses ${ }^{105}$ and two formal ones have been published. ${ }^{106}$ The first total synthesis of abyssomicin was reported in 2005 by Sorensen and his coworkers. ${ }^{105 a}$ Their strategy is based on a biomimetic intramolecular Diels-Alder reaction of linear precursor 168.

The trienone 168 was generated from the $\beta$-elimination of $\mathbf{1 6 9}$ upon exposure to scandium(III) triflate (Scheme 56). The resulting Diels-Alder precursor 168 proved to be unstable, but succeeded in giving the desired cycloadduct $\mathbf{1 7 0}$ when a solution of the trienone 168 in toluene was heated to $100{ }^{\circ} \mathrm{C}$ for four hours. The authors elegantly managed to overcome this problem of stability by developing a one-pot domino process (elimination and $[4+2]$ cycloaddition) starting from compound $\mathbf{1 6 9}$. Accordingly, the tricyclic structure $\mathbf{1 7 0}$ was generated in one step from diene 169 in presence of the Lewis acid lanthanum(III) triflate. Both methods were highly diastereoselective and allowed them to build the spiro quaternary stereocentre. No other regioisomeric cycloadducts were detected. This excellent diastereoselectivity has been rationalised by the authors after calculation of the energies of the different possible transition states. It was concluded that the lowest-energy transition-state conformation resembled II, where the two carbonyl groups adopt an anti relationship.

This asymmetric synthesis of abyssomicin proceeded in fifteen steps (for the longest linear sequence). Notably, the biomimetic intramolecular diastereoselective Diels-Alder step was also used by Snider ${ }^{106 a}$ and Couladoros ${ }^{106 b}$ as a part of their formal syntheses of abyssomicin.

(d) Synthesis of tokinolide B. Levistolide A (171) and tokinolide B (172), which were isolated from the rhizome of Ligusticum and Cnidium species, are active constituents of traditional Chinese herbal medicine (Scheme 57). ${ }^{107}$ These dimers of ligustilide $\mathbf{1 4 5}$ have been reported to display potent vasodilatory

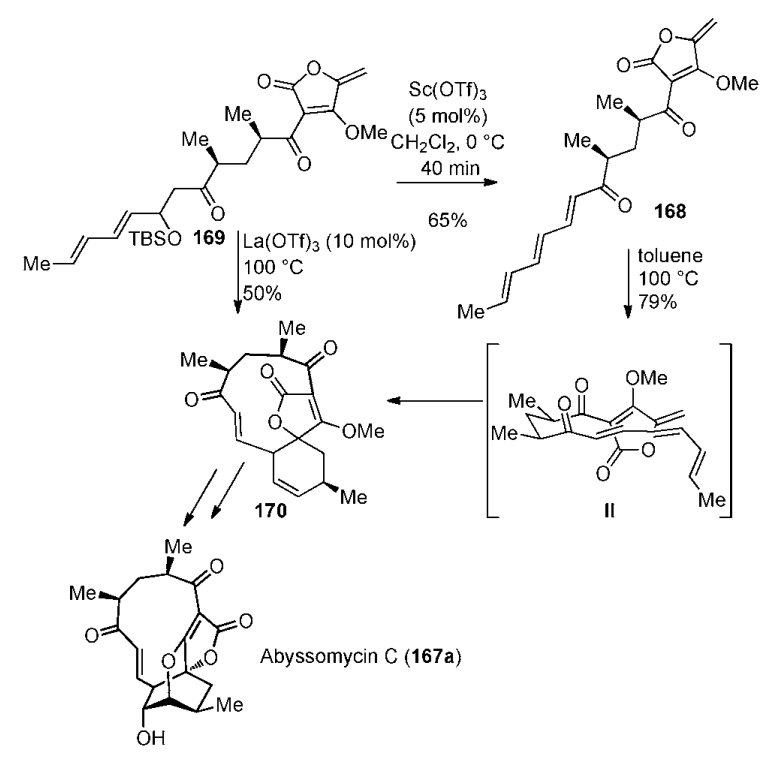

Scheme 56 activity depending predominantly on their $\mathrm{Ca}^{2+}$-channel blocker properties. ${ }^{107 e}$ In addition, levistolide $\mathrm{A}$ has been shown to overcome P-glycoprotein-mediated drug resistance in human breast carcinoma cells. ${ }^{108}$ From a structural point of view, these two pentacyclic structures have four stereocentres each and are found as racemates in Nature. To date, only one total synthesis of these two natural products has been reported. ${ }^{109}$ Wakamatsu et al. strategy employed a Diels-Alder reaction to access both dimers 171 and 172. Accordingly, a solution of ligustilide $\mathbf{1 4 5}^{\mathbf{1 1 0}}$ in benzene was heated to reflux and afforded 2 and $4 \%$ of endo adducts 171 and 172 respectively, along with $56 \%$ of the starting material. Despite the use of Lewis acids or high-pressure conditions, the reaction still proceeded in low yield. When the temperature of the reaction mixture was raised to $200{ }^{\circ} \mathrm{C}, 23 \%$ of dimer 171 along with $60 \%$ of starting material were obtained. From these results, it was deduced that the high recovery of starting material was the result of the competing retro-DielsAlder reaction, that the endo approach was preferred due to secondary orbital interactions, and finally that $\mathbf{1 7 2}$ was converted to the thermodynamically more stable compound $\mathbf{1 7 1}$.

(e) Synthesis of deoxy-lambertellols. Very recently, Commeiras and Parrain ${ }^{111}$ have reported an efficient synthesis of deoxylambertellols 173 via a highly chemo- and diastereoselective intermolecular Diels-Alder cycloaddition between trans-1,2disiloxybenzocyclobutenes $\mathbf{1 7 4}$ and 2-methylprotoanemonine 175 (Scheme 58). At $50{ }^{\circ} \mathrm{C}$ in degassed benzene, [4+2] cycloaddition of $\mathbf{1 7 4}$ and $\mathbf{1 7 5}$ occurred within four hours, affording chemoselectively the desired spirolactone $\mathbf{1 7 6}$ with complete endo-stereoselectivity in $87 \%$ yield. With the carbon skeleton of lambertellols in hand, the authors carried on the synthesis to the simplified deoxy-lambertellols C and B $\mathbf{1 7 3 .}$

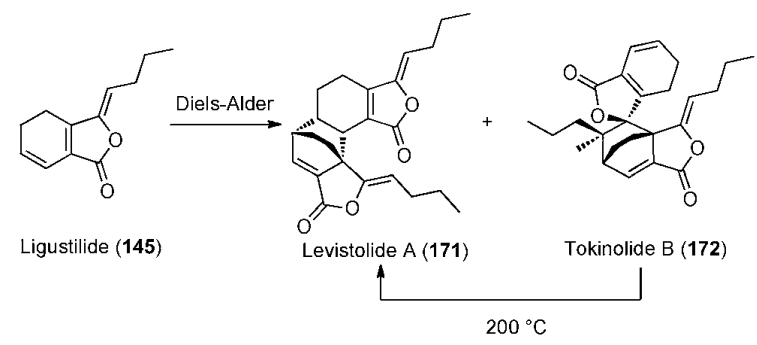

Scheme 57

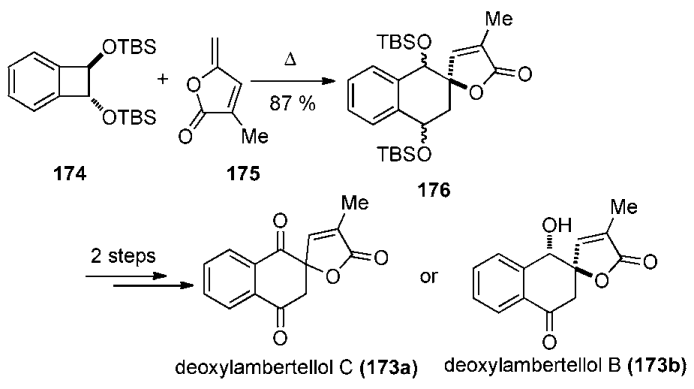

Scheme 58 


\section{$9.5[3+2]-$ type cyclisation}

In 1997, Nair reported a new route to spirolactones via a triphenylphosphine-mediated-[3 + 2] cyclisation between dimethylacetylene dicarboxylate and either 1,2- or 1,4-benzoquinone 177 (Scheme 59). ${ }^{112}$ During the course of this reaction, a catalytic amount of phosphine $(50 \mathrm{~mol} \%)$ first adds to the alkynone in a 1,4-fashion. The resulting zwitterionic species $\mathbf{1 7 8}$ then adds onto one of the two ketones present on 177. Finally, cyclisation of intermediate $\mathbf{1 7 9}$ followed by elimination of the phosphine provides the spirolactone incorporating a ketone $\alpha$ (or $\gamma$ if 1,4benzoquinone is used) to the fused quaternary carbon $\mathbf{1 8 2}$. Only one step was required to access bicyclic compound starting from readily available and simple starting materials. However, the limitation of the method lies in the exclusive use of DMAD. A few years later, Esmaili and Bodaghi used the same procedure for the addition of dimethylacetylene dicarboxylate to istatin derivatives. ${ }^{113}$

The cycloaddition strategy allows rapid access to complex polycyclic structures, especially in the intramolecular version of the Diels-Alder reaction. One limitation of this approach can be the instability of the diene employed. On the other hand, if these dienes are easily accessible, the chemist has at their disposal a powerful synthetic tool for the synthesis of the corresponding spiro compounds.

\section{Miscellaneous}

\subsection{1,6-Addition}

Reaction of protoanemonin 143 and a dimethyl malonate anion led to the formation of two spiro molecules 183 and 184 in 22 and $17 \%$ respectively via consecutive 1,6-additions (Scheme 60). ${ }^{114}$

\subsection{Dyotropic rearrangement}

Having a spiro butyrolactone regioselectively substituted at the $\alpha$ carbon of the lactone ring presents a challenge from a synthetic

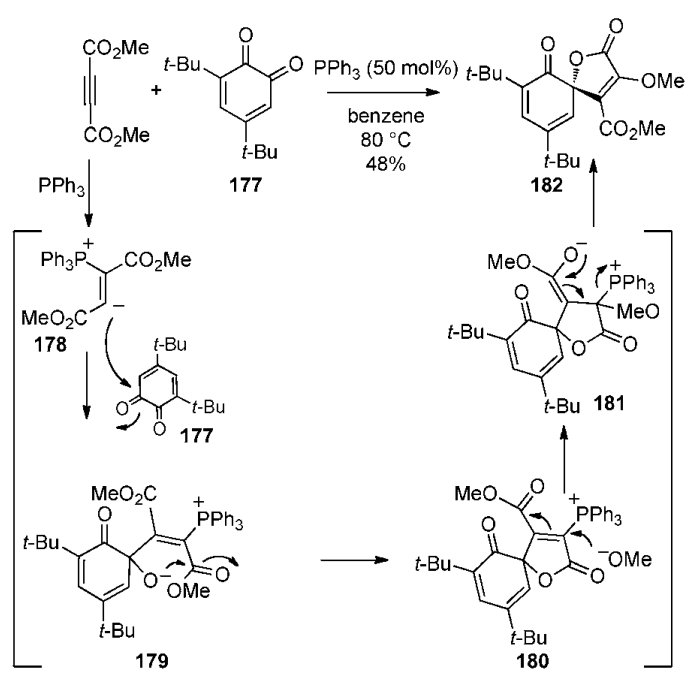

Scheme 59

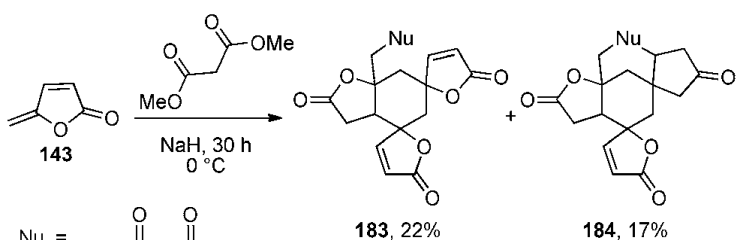

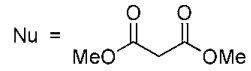

183, $22 \%$

$184,17 \%$

Scheme 60

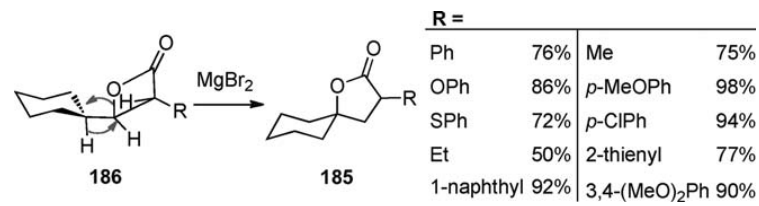

Scheme 61

point of view. Black et al. reported a sequence in only three steps starting from readily available starting materials to reach efficiently $\alpha$-substituted spiro butyrolactone 185 (Scheme 61). ${ }^{115}$ This methodology is based on a stereoselective dyotropic rearrangement. During this process, two $\sigma$-bonds simultaneously migrate intramolecularly. The concerted nature of this transformation requires an antiperiplanar alignment of the migrating bonds and hydride migrate preferentially compared to carbon.

In a typical procedure a solution of propiolactone derivative 186 in diethyl ether was treated with one equivalent of magnesium bromide etherate for six hours and the corresponding bicyclic molecule fused at a central carbon was obtained in excellent yield and with complete retention of the stereochemistry.

This expedient hydride transformation in which a ring expansion of $\beta$-lactone was accompanied by migration provides easy access to $\alpha$-substituted spiro butyrolactones. However, this method is limited to appended six-membered rings. The migratory aptitude is also dependent on energetic factors, such as the release of strain in a pendant cycloalkyl ring, and no spiro compound was detected with a five-membered ring; instead, the fused spirobutyrolactone was isolated.

\section{Conclusion}

Various methods for the synthesis of spirolactones concomitantly with the quaternary stereocentre have been discussed. They provide rapid entry into a diverse range of highly relevant (natural and/or biologically defined targets) and sterically constrained architectures, and ones for which the quaternary centre is often implicated in the bioactivity of the natural product. These methods are also often accompanied by high diastereoselectivities, especially in their intramolecular versions. However, a lack of general enantioselective approaches remains, and this area is still in its infancy. This has been partly solved in the case of phenolic oxidation to quinones by the development of an asymmetric catalyst by Kita and Ishihara, although this method is unfortunately limited to this type of substrate. The development of a suitable chiral catalyst for the cycloaddition reactions could lead to general enantioselective approaches to 
spirolactones. Finally, it would be interesting, from a structureactivity relationship point of view, to understand the role played by the strained spiro-structure when compared to the corresponding tertiary alcohol.

\section{Acknowledgements}

The Agence Nationale pour la Recherche (A.N.R.-09-JCJC0036), the C.N.R.S. and the Université Paul Cézanne (UMR 6263) are gratefully acknowledged for financial support. The authors wish to thank Dr Stephen Dalby for his advice and many useful comments during the preparation of this document.

\section{References}

1 W. Elger, S. Beier, K. Pollow, R. Garfield, S. Q. Shi and A. Hillisch, Steroids, 2003, 68, 891-905 and references therein

$2 \mathrm{http}: / / \mathrm{www} . c h e m . c o r n e l l . e d u / j n 96 /$ outreach.html.

3 (a) B. Bister, D. Bischoff, M. Strobele, J. Riedlinger, A. Reicke, F. Wolter, A. T. Bull, H. Zahner, H. P. Fiedler and R. D. Süssmuth, Angew. Chem., Int. Ed., 2004, 43, 2574-2576; (b) J. Riedlinger, A. Reicke, H. Zahner, B. Krismer, A. T. Bull, L. A. Maldonado, A. C. Ward, M. Goodfellow, B. Bister, D. Bischoff, R. D. Süssmuth and H. P. Fiedler, J. Antibiot., 2004 57, 271-279.

4 (a) J. Christoffers and A. Baro, Adv. Synth. Catal., 2005, 347, 14731482; (b) C. J. Douglas and L. E. Overman, Proc. Natl. Acad. Sci U. S. A., 2004, 101, 5363-5367; (c) E. A. Peterson and L. E. Overman, Proc. Natl. Acad. Sci. U. S. A., 2004, 101, 11943 11948

5 L. Barriault and D. H. Deon, Org. Lett., 2001, 3, 1925-1927.

6 C. H. Heathcock and T. W. Vongeldern, Heterocycles, 1987, 25, 75

7 P. Liu, S. Hong and S. M. Weinreb, J. Am. Chem. Soc., 2008, 130 $7562-7564$.

8 (a) T. Taniguchi and H. Ishibashi, Tetrahedron, 2008, 64, 8773-8779, (b) T. Taniguchi, G. Tanabe, O. Muraoka and H. Ishibashi, Org. Lett., 2008, 10, 197-199.

9 S. Kotha, A. Chandra Deb, K. Lahiri and E. Manivannan, Synthesis, 2009, 165-193.

10 M. Sannigrahi, Tetrahedron, 1999, 55, 9007-9071.

11 B. Rama Raju and A. K. Saikia, Molecules, 2008, 13, 1942 2038

12 S. Rosenberg and R. Leino, Synthesis, 2009, 2651-2673.

13 E. J. Corey and L. F. Haefele, J. Am. Chem. Soc., 1959, 81, 225 2228

14 (a) I. G. C. Coutts, M. Edwards, D. R. Musto and D. J. Richards, Tetrahedron Lett., 1980, 21, 5055-5056; (b) I. G. C. Coutts, N. J. Culbert, M. Edwards, J. A. Hadfield, D. R. Musto, V. H. Pavlidis and D. J. Richards, J. Chem. Soc., Perkin Trans. I, $1985,1829-1836$

15 Y. Tamura, T. Yakura, J.-i. Haruta and Y. Kita, J. Org. Chem. 1987, 52, 3927-3931.

16 N. Kotoku, H. Tsujita, A. Hiramatsu, C. Mori, N. Koizumi and M. Kobayashi, Tetrahedron, 2005, 61, 7211-7218.

17 H. Hara, T. Inoue, H. Nakamura, M. Endoh and O. Hoshino, Tetrahedron Lett., 1992, 33, 6491-6494.

18 (a) F. Wessely and F. Sinwel, Monatsh. Chem., 1950, 81, 1055-1070 (b) M. Metlesics, E. Schinzel, H. Vilcsek and F. Wessely, Monatsh. Chem., 1957, 88, 1069-1076.

19 I. Drutu, J. T. Njardarson and J. L. Wood, Org. Lett., 2002, 4, 493 496

20 T. Dohi, A. Maruyama, M. Yoshimura, K. Morimoto, H. Tohma and Y. Kita, Angew. Chem., Int. Ed., 2005, 44, 6193-6196.

21 T. Dohi, A. Maruyama, N. Takenaga, K. Senami, Y. Minamitsuji, H. Fujioka, S. B. Caemmerer and Y. Kita, Angew. Chem., Int. Ed., 2008, 47, 3787-3790.

22 M. Uyanik, T. Yasui and K. Ishihara, Angew. Chem., Int. Ed., 2010 49, 2175-2177.

23 (a) H. W. Fehlhaber, H. Kogler, T. Mukhopadhyay, E. K. S. Vijayakumar and B. N. Ganguli, J. Antibiot., 1988, 41,
1785-1794; (b) H. W. Fehlhaber, H. Kogler, T. Mukhopadhyay, E. K. S. Vijayakumar and B. N. Ganguli, J. Am. Chem. Soc. 1988, 110, 8242-8244; (c) K. Roy, T. Mukhopadhyay, G. C. Reddy, K. R. Desikan, R. H. Rupp and B. N. Ganguli, J. Antibiot., 1988, 41, 1780-1784.

24 K. Roy, E. K. S. Vijayakumar, T. Mukhopadhyay, S. Chatterjee, R. G. Bhat and B. N. Ganguli, J. Antibiot., 1992, 45, 1592-1598.

25 T. Mukhopadhyay, R. G. Bhat, K. Roy, E. K. S. Vijayakumar and B. N. Ganguli, J. Antibiot., 1998, 51, 439-441.

26 E. K. S. Vijayakumar, K. Roy, S. Chatterjee, T. Mukhopadhyay, R. G. Bhat and B. N. Ganguli, J. Antibiot., 1998, 51, 522-524.

27 T. Nakashima, R. Tanaka, Y. Yamashita, Y. Kanda and M. Hara, Biochem. Biophys. Res. Commun., 2008, 377, 1085-1090.

28 (a) A. McKillop, L. McLaren, R. J. Watson, R. J. K. Taylor and N. Lewis, Tetrahedron Lett., 1993, 34, 5519-5522; (b) P. Wipf, Y. Kim and P. C. Fritch, J. Org. Chem., 1993, 58, 7195-7203; (c) P. Wipf and Y. Kim, J. Org. Chem., 1993, 58, 1649-1650.

29 A. V. Rama Rao, M. K. Gurjar and P. A. Sharma, Tetrahedron Lett., 1991, 32, 6613-6616.

30 R. Takagi, W. Miyanaga, K. Tojo, S. Tsuyumine and K. Ohkata, J. Org. Chem., 2007, 72, 4117-4125.

31 (a) M. Tanaka, F. Nara, K. Suzuki-Konagai, T. Hosoya and T. Ogita, J. Am. Chem. Soc., 1997, 119, 7871-7872; (b) F. Nara M. Tanaka, T. Hosoya, K. Suzuki-Konagai and T. Ogita, J. Antibiot., 1999, 52, 525-530; (c) F. Nara, M. Tanaka, S. Masuda-Inoue, Y. Yamasato, H. Doi-Yoshioka, K. SuzukiKonagai, S. Kumakura and T. Ogita, J. Antibiot., 1999, 52, 531-535.

32 (a) C. Arenz and A. Giannis, Angew. Chem., Int. Ed., 2000, 39, 1440 1442; (b) C. Arenz, M. Gartner, V. Wascholowski and A. Giannis, Bioorg. Med. Chem., 2001, 9, 2901-2904; (c) C. Arenz and A. Giannis, Eur. J. Org. Chem., 2001, 137-140; (d) C. Arenz, M. Thutewohl, O. Block, H. Waldmann, H.-J. Altenbach and A. Giannis, ChemBioChem, 2001, 2, 141-143; (e) E. N. Pitsinos, V. Wascholowski, S. Karaliota, C. Rigou, E. A. Couladouros and A. Giannis, ChemBioChem, 2003, 4, 1223-1225; $(f)$ R. A. Claus, A. Wüstholz, S. Müller, C. L. Bockmeyer, N. H. Riedel, R. Kinscherf and H.-P. Deigner, ChemBioChem, 2005, 6, 726-737; (g) V. Wascholowski and A. Giannis, Angew. Chem., Int. Ed. 2006, 45, 827-830; (h) V. Wascholowski, A. Giannis and E. N. Pitsinos, ChemMedChem, 2006, 1, 718-721. For total syntheses, see: (i) M. Inoue, W. Yokota, M. G. Murugesh, T. Izuhara and T. Katoh, Angew. Chem., Int. Ed., 2004, 43, 42074209; (j) R. Takagi, W. Miyanaga, K. Tojo, S. Tsuyumine and K. Ohkata, J. Org. Chem., 2007, 72, 4117-4125; (k) H. Fujioka, Y. Sawama, N. Kotoku, T. Ohnaka, T. Okitsu, N. Murata, O. Kubo, L. Ruichuan and Y. Kita, Chem.-Eur. J., 2007, 13, 10225-10238; (l) M. Inoue, W. Yokota and T. Katoh, Synthesis, 2007, 622-637; ( $m$ ) E. Pitsinos, N. Athinaios, Z. Xu, G. wang and E.-i. Negishi, Chem. Commun., 2010, 46, 2200-2202.

33 S. Fukuzawa, A. Nakanishi, T. Fujinami and S. Sakai, J. Chem. Soc. Chem. Commun., 1986, 624-625.

34 K. Otsubo, J. Inanaga and M. Yamaguchi, Tetrahedron Lett., 1986, 27, 5763-5764.

35 M. Kaname and S. Yoshifuji, Tetrahedron Lett., 1992, 33, 8103 8104.

36 (a) J. Lamotte, B. Oleksyn, L. Dupont, O. Dideberg, H. Campsteyn and M. Vermeire, Acta Crystallogr., Sect. B, 1978, 34, 3625-3638; (b) N. R. Banga, A. Welter, J. Jadot and J. Casimir, Phytochemistry, $1979, \mathbf{1 8}, 482-484$

37 C. A. Merlic and J. C. Walsh, J. Org. Chem., 2001, 66, 2265-2274.

38 W. Zhang and G. Pugh, Tetrahedron Lett., 1999, 40, 7595-7598.

39 (a) W. Zhang, Tetrahedron Lett., 2000, 41, 2523-2527; (b) W. Zhang and G. Pugh, Tetrahedron Lett., 2001, 42, 5617-5620.

40 W. Zhang and G. Pugh, Tetrahedron Lett., 2001, 42, 5617-5620.

41 D. P. Curran, M.-H. Chen, E. Spletzer, C. Min Seong and C.-T. Chang, J. Am. Chem. Soc., 1989, 111, 8872-8878.

42 K. Kobayashi, M. Itoh and H. Suginome, Tetrahedron Lett., 1987 , 28, 3369-3372.

43 N. Maulide and I. E. Markó, Org. Lett., 2006, 8, 3705-3707.

44 M. Abe, S. Ohmono, T. Ohashi and T. Tabuchi, Agric. Biol. Chem. $1969,33,469-471$

45 R. J. Cole, J. W. Kirksey, J. Clardy, N. Eickman, S. M. Weinreb, P. Singh and D. Kim, Tetrahedron Lett., 1976, 17, 3849-3952.

46 J. W. Dorner, R. J. Cole, R. Hill, D. Wicklow and R. H. Cox, Appl. Environ. Microbiol., 1980, 40, 685-687. 
47 V. P. Zhelifonova, T. V. Antipova, S. M. Ozerkaya, N. E. Ivanushkina and A. G. Kozlovskii, Microbiology, 2006, 75 644-648.

48 I. Ninomiya and T. Kiguchi, in The Alkaloids, ed. A. Brossi, Academic Press: San Diego, CA, 1990, vol. 38, pp. 1-156.

49 S. Yamatodani, Y. Asahi, A. Matsukura and M. Abe, Agric. Biol. Chem., 1970, 34, 485-487.

50 (a) J. Rebek and Y.-K. Shue, J. Am. Chem. Soc, 1980, 102, 5426 5427; (b) J. Rebek and Y.-K. Shue, J. Org. Chem., 1984, 49, 3540 3545; (c) S. F. Martin and S. Liras, J. Am. Chem. Soc., 1993, 115 10450-10451; (d) S. Liras, C. Lynch, A. Fryer, B. T. Vu and S. F. Martin, J. Am. Chem. Soc., 2001, 123, 5918-5924.

51 S. F. Martin, K. J. Barr, D. W. Smith and S. Bur, J. Am. Chem. Soc., 1999, 121, 6990-6997.

52 T. Noro, S. Fukushima, A. Ueno, T. Miyase and Y. Itaka, Chem. Pharm. Bull., 1979, 27, 1495-1497.

53 R.-W. Jiang, P.-M. Hon, Y. Zhou, Y.-M. Chan, Y.-T. Xu, H.-X. Xu, H. Greger, P.-C. Shaw and P. P.-H. But, J. Nat. Prod., 2006, 69, 749 754.

54 C.-P. Tang, T. Chen, R. Velten, P. Jeschke, U. EbbinghausKintscher, S. Geibel and Y. Ye, J. Nat. Prod., 2008, 71, 112-116.

55 H. Greger, J. Schinnerl, S. Vajrodaya, L. Brecker and O. Hofer, J. Nat. Prod., 2009, 72, 1708-1711.

56 Jiangsu New Medical College, Dictionary of Chinese Traditional Medicine, Shanghai People's Publishing House, 1977, pp. 858-861.

57 (a) L.-G. Lin, H. P.-H. Leung, J.-Y. Zhu, C.-P. Tang, C.-Q. Ke, J. A. Rudd, G. Lin and Y. Ye, Tetrahedron, 2008, 64, 10155 10161; (b) Y. T. Xu, P.-M. Hon, R.-W. Jiang, L. Chen, S.-H. Li, Y.-P. Chan, H.-X. Xu, P.-C. Shaw and P. P.-H. But, J. Ethnopharmacol., 2006, 108, 46-53.

58 Y. Ye, G.-W. Qin and R.-S. Xu, J. Nat. Prod., 1994, 57, 665669.

59 (a) Effects of T-2 on in vitro proliferation of human cancer cell line $\left(\mathrm{IC}_{50}\right.$ in $\left.\mu \mathrm{M}\right)$ : MimaPaca-2, 5.9; SW480, 5.8; HCT116, 6.2; $(b)$ Effects of $\mathrm{T}-5$ on in vitro proliferation of human cancercell line $\left(\mathrm{IC}_{50}\right.$ in $\left.\mu \mathrm{M}\right)$ : MimaPaca-2, 22.9; SW480, 15.4; HCT116, 14.

60 Y.-Y. Li, Y.-Y. Wang, T. Taniguchi, T. Kawakami, T. Baba, H. Ishibashi and N. Mukaida, Int J Cancer, 2010, 127, 474 484.

61 (a) A. S. Kende, J. I. M. Hernando and J. B. J. Milbank, Org. Lett., 2001, 3, 2505-2508; (b) A. S. Kende, J. I. M. Hernando and J. B. J. Milbank, Tetrahedron, 2002, 58, 61-74.

62 T. Murakami, Y. Morikawa, M. Hashimoto, T. Okuno and Y. Harada, Org. Lett., 2004, 6, 157-160.

63 T. Murakami, A. Sasaki, E. Fukushi, J. Kawabata, M. Hashimoto and T. Okuno, Bioorg. Med. Chem. Lett., 2005, 15, 2587-2590.

64 (a) T. Murakami, N. Takada, Y. Harada, T. Okuno and M. Hashimoto, Biosci., Biotechnol., Biochem , 2007, 71, 1230-1235; (b) T. Murakami, Y. Takahashi, E. Fukushi, J. Kawabata, M. Hashimoto, T. Okuno and Y. Harada, J. Am. Chem. Soc. 2004, 126, 9214-9220.

65 M. Nomiya, T. Murakami, N. Takada, T. Okuno, Y. Harada and M. Hashimoto, J. Org. Chem., 2008, 73, 5039-5047.

66 Y. Shiobara, T. Iwata, M. Kodama, Y. Asakawa, T. Takemoto and Y. Fukazawa, Tetrahedron Lett., 1985, 26, 913-916.

67 R. A. Abramovitch, A. Hawi, J. A. Rodrigues and T. R. Trombetta, J. Chem. Soc., Chem. Commun., 1986, 283-284.

68 M.-C. Yeh, Y.-C. Lee and T.-C. Young, Synthesis, 2006, 3621-3624

69 (a) P. Canonne, M. Akssira and G. Lemay, Tetrahedron Lett., 1981 22, 2611-2614; (b) P. Canonne, R. Boulanger and M. Bernatchez, Tetrahedron Lett., 1987, 28, 4997-5000; (c) P. Canonne, R. Boulanger and P. Angers, Tetrahedron Lett., 1991, 32, 58615864

70 (a) H. Pellissier, S. Wilmouth and M. Santelli, Bull. Soc. Chim. Fr. 1995, 132, 637-641; (b) P.-Y. Michellys, H. Pellissier and M. Santelli, Tetrahedron Lett., 1993 , 34, 1931-1934; (c) P. Y. Michellys, P. Maurin, L. Toupet, H. Pellissier and M. Santelli, J. Org. Chem., 2001, 66, 115-122.

71 F. Machrouchi and J.-L. Namy, Tetrahedron, 1998, 54, 1111111122

72 R. Csuk, Z. Hu, M. Abdou and C. Kratky, Tetrahedron, 1991, 47, 70737-7044.

73 Y. Rollin, S. Derien, E. Duñach, C. Gebehenne and J. Perichon, Tetrahedron Lett., 1993, 49, 7723-7732.

74 E. Fouquet, A. Gabriel, B. Maillard and M. Pereyre, Tetrahedron Lett., 1993, 34, 7749-7752.
75 P. K. Choudhury, F. Foubelo and M. Yus, Tetrahedron Lett., 1998, 39, 3581-3584.

76 R. Csuk, B. I. Glänzer, Z. Hu and R. Boese, Tetrahedron, 1994, 50, 1111-1124.

77 M. S. Sawant, R. Katoch, G. K. Trivedi and U. R. Desai, J. Chem Soc., Perkin Trans. 1, 1998, 843-846.

78 A. P. Rauter, J. Figueiredo, M. Ismael, T. Canda, J. Font and M. Figueredo, Tetrahedron: Asymmetry, 2001, 12, 1131-1146.

79 F. Sánchez-Izquierdo, P. Blanco, F. Busqué, R. Alibés, P. de March, M. Figueredo, J. Font and T. Parella, Org. Lett., 2007, 9, 1769-1772.

$80 \mathrm{~K}$. Sakata, K. Aoki, C.-F Chang, A Sakurai, S. Tamura and S. Murakoshi, Agric. Biol. Chem., 1978, 42, 457-463.

81 H. Xiong and R. D. Rieke, J. Org. Chem., 1992, 57, 7007-7008.

82 S. Ogoshi, K.-i. Tonomori, M.-a. Oka and H. Kurosawa, J. Am Chem. Soc., 2006, 128, 7077-7086.

83 A. K. Mandal and D. G. Jawalkar, Tetrahedron Lett., 1986, 27, 99 100 .

84 (a) C. Wawrzeńczyk, Z. Ciunik and E. Paruch, Eur. J. Org. Chem., 1998, 2677-2682; (b) S. Lochyński, B. Frạckowiak, T. Olejniczak, Z. Ciunik and C. Wawrzeńczyk, Tetrahedron: Asymmetry, 2002, 13, 1761-1767.

85 X. Zhang and R. C. Larock, J. Am. Chem. Soc., 2005, 127, 12230 12231 .

86 B.-X. Tang, Q. Yin, R.-Y. Tang and J.-H. Li, J. Org. Chem., 2008, 73, 9008-9011.

87 H. Salim and O. Piva, Tetrahedron Lett, 2008, 49, 2994-2995.

88 R. D. Miller, W. Theis, G. Heilig and S. Kirchmeyer, J. Org. Chem. 1991, 56, 1453-1463.

89 H. Tomioka and K. Yamamoto, J. Chem. Soc., Chem. Commun. 1995, 1961-1962.

90 (a) B. Quiroz-García, R. Figueroa, J. Antonio Cogordan and G. Delgado, Tetrahedron Lett., 2005, 46, 3003-3006; (b) B. Doroh and G. A. Sulikowski, Org. Lett., 2006, 8, 903-906.

91 M. Yamamoto, H. Izukawa, M. Saiki and K. Yamada, J. Chem Soc., Chem. Commun., 1988, 560-561.

92 W. E. Campbell, G. M. L. Cragg and A. H. Powrie, Phytochemistry, 1979, 18, 323-324.

93 J. Marrero, A. D. Rodríguez, P. Baran, R. G. Raptis, J. A. Sánchez, E. Ortega-Barria and T. L. Capson, Org. Lett. 2004, 6, 1661-1664.

94 R. M. Ortuño, J. Corbera and J. Font, Tetrahedron Lett., 1986, 27, 1081-1084.

95 A. J. Poss and M. H. Brodowski, Tetrahedron Lett., 1989, 30, 2505 2508

96 K. Okumura, K. Okazaki, K. Takeda and E. Yoshii, Tetrahedron Lett., 1989, 30, 2233-2236.

97 (a) D. Alonso, J. Ortí, V. Branchadell, A. Oliva, R. M. Ortuño, J. Bertrán and J. Font, J. Org. Chem., 1990, 55, 3060-3063; (b) V. Branchadell, J. Font, A. Oliva, J. Ortí and R. M. Ortuño, Tetrahedron, 1991, 47, 8775-8786; (c) D. Alonso, J. Font and R. M. Ortuño, J. Org. Chem., 1991, 56, 5567-5572; (d) C. Ochoa de Echagüen and R. M. Ortuño, Tetrahedron Lett, 1995, 36, 749 752; (e) V. Branchadell, J. Font, A. G. Moglioni, C. Ochoa de Echagüen, A. Oliva, R. M. Ortuño, J. Veciana and J. VidalGancedo, J. Am. Chem. Soc., 1997, 119, 9992-10003.

98 S. Rafel, G. Cabarrocas, M. Ventura and T. Parella, J. Chem. Soc., Perkin Trans. 1, 1998, 3837-3843.

99 W. Hofheinz and P. Schoenholzer, Helv. Chim. Acta, 1977, 60, 1367 1370

100 R. P. Gregson and D. Ouvrier, J. Nat. Prod., 1982, 45, 412-414.

101 J. Uenishi, R. Kawahama, T. Imakoga and O. Yonemitsu, Chem. Pharm. Bull., 1998, 46, 1090-1093.

102 K. Takeda, M.-a. Sato and E. Yoshii, Tetrahedron Lett., 1986, 27, 3903-3906.

103 J. Uenishi, R. Kawahama and O. Yonemitsu, J. Org. Chem., 1997, 62, 1691-1701.

104 (a) K. C. Nicolaou, S. T. Harrison and J. S. Chen, Synthesis, 2009 33-42; (b) A. L. Zografos and D. Georgiadis, Synthesis, 2006, 3157-3188.

105 (a) C. W. Zapf, B. A. Harrison, C. Drahl and E. J. Sorensen, Angew. Chem., Int. Ed., 2005, 44, 6533-6537; (b) K. C. Nicolaou and S. T. Harrison, Angew. Chem., Int. Ed., 2006, 45, 3256-3260; (c) K. C. Nicolaou, R. M. Denton, A. Lenzen, D. J. Edmonds, A. Li, R. R. Milburn and S. T. Harrison, Angew. Chem., Int. Ed., 2006, 45, 2076-2081. 
106 (a) B. B. Snider and Y. F. Zou, Org. Lett., 2005, 7, 4939-4941; (b) E. A. Couladouros, E. A. Bouzas and A. D. Magos, Tetrahedron, 2006, 62, 5272-5279.

107 (a) M. Kaouadji, F. Depachtere, C. Pouget, A. J. Chulia and S. Lavaitte, J. Nat. Prod., 1986, 49, 872-877; (b) M. Kobayashi, M. Fujita and H. Mitsuhashi, Chem. Pharm. Bull., 1987, 35, 1427 1433; (c) G. Delgado, R. G. Rezagarduno, R. A. Toscano, R. Bye and E. Linares, Heterocycles, 1988, 27, 1305-1312; (d) T. Tsuchida, M. Kobayashi, K. Kaneko and H. Mitsuhashi, Chem. Pharm. Bull., 1987, 35, 4460-4464; (e) T. Naito, T. Katsuhara, K. Niitsu, Y. Ikeya, M. Okada and H. Mitsuhashi, Heterocycles, 1991, 32, 2433-2442.

108 F. Chen, T. Wang, J. Wang, Z. Q. Wang and M. Qian, ActaPharmacol. Sin., 2008, 29, 458-464.

109 Y. Ogawa, Y. Mori, M. Maruno and T. Wakamatsu, Heterocycles, $1997,45,1869-1872$
110 (a) Y. Ogawa, M. Maruno and T. Wakamatsu, Heterocycles, 1995, 41, 2587-2599; (b) Y. Ogawa, M. Maruno and T. Wakamatsu, Synlett, 1995, 871-872.

111 R. Blanc, V. Héran, R. Rahmani, L. Commeiras and J.-L. Parrain, Org. Biomol. Chem., 2010, 8, 5490-5494.

112 (a) V. Nair, J. Somarajan Nair, A. U. Vinod and N. P. Rath, J. Chem. Soc. Perkin Trans. 1, 1997, 3129-3130; (b) V. Nair, J. Somarajan Nair and A. U. Vinod, Synthesis, 2000, 17131718

113 A. E. Esmaili and A. Bodaghi, Tetrahedron, 2003, 59, 1169 1171

114 J. Bigorra, J. Font, C. Jaime, R. M. Ortuño and F. SanchezFerrando, Tetrahedron, 1985, 41, 5577-5587.

115 (a) T. H. Black and W. J. Dubay III, Tetrahedron Lett., 1987, 28 4787-4788; (b) T. H. Black, W. J. Dubay III and P. S. Tully, J. Org. Chem., 1988, 53, 5922-5927. 